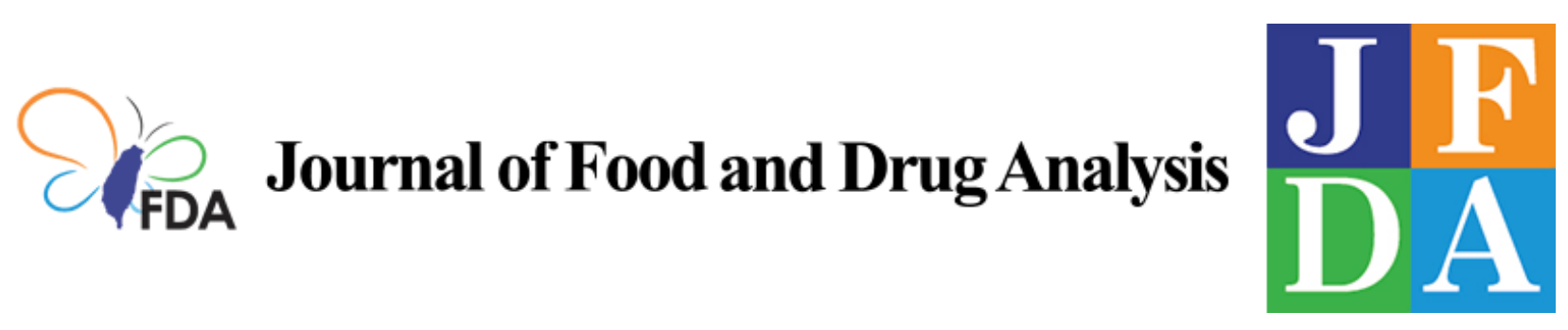

Volume 29 | Issue 4

Article 8

2021

\title{
Identification of oxytocin receptor activating chemical components from traditional Japanese medicines
}

Follow this and additional works at: https://www.jfda-online.com/journal

Part of the Food Science Commons, Medicinal Chemistry and Pharmaceutics Commons, Pharmacology Commons, and the Toxicology Commons

(c) (1) (9)

This work is licensed under a Creative Commons Attribution-Noncommercial-No Derivative Works 4.0 License.

\section{Recommended Citation}

Maejima, Yuko; Horita, Shoichiro; Yokota, Shoko; Ono, Tomoyuki; Proks, Peter; Yoshida-Komiya, Hiromi; Ueta, Yoichi; Nishimori, Katsuhiko; Misaka, Shingen; and Shimomura, Kenju (2021) "Identification of oxytocin receptor activating chemical components from traditional Japanese medicines," Journal of Food and Drug Analysis: Vol. 29 : Iss. 4 , Article 8.

Available at: https://doi.org/10.38212/2224-6614.3381

This Original Article is brought to you for free and open access by Journal of Food and Drug Analysis. It has been accepted for inclusion in Journal of Food and Drug Analysis by an authorized editor of Journal of Food and Drug Analysis. 


\title{
Identification of oxytocin receptor activating chemical components from traditional Japanese medicines
}

\author{
Yuko Maejima ${ }^{a, * *}$, Shoichiro Horita ${ }^{a}$, Shoko Yokota ${ }^{a}$, Tomoyuki Ono ${ }^{\text {, }}$, Peter Proks ${ }^{b}$, \\ Hiromi Yoshida-Komiya ${ }^{c}$, Yoichi Ueta ${ }^{\mathrm{d}}$, Katsuhiko Nishimori ${ }^{\mathrm{a}}$, \\ Shingen Misaka ${ }^{a}$, Kenju Shimomura ${ }^{a, *}$ \\ ${ }^{\text {a }}$ Department of Bioregulation and Pharmacological Medicine, Fukushima Medical University School of Medicine, Fukushima, 960-1295, \\ Japan \\ b Oxford Centre for Gene Function, University of Oxford, Oxford, OX1 3PT, United Kingdom \\ ${ }^{c}$ Gender Specific Medical Centre, Fukushima Medical University School of Medicine, Fukushima, 960-1295, Japan \\ d Department of Physiology, School of Medicine, University of Occupational and Environmental Health, Kita-Kyushu, 807-8555, Japan
}

\begin{abstract}
Oxytocin (Oxt) is known to regulate social communication, stress and body weight. The activation of Oxt receptors (OTR) has clinical potential to abate stress disorders and metabolic syndrome. Kamikihito (KKT) is a traditional Japanese medicine used to treat psychological stress-related disorders. We investigated the effects of KKT, its ingredients and chemical components on Oxt neurons and OTR. C-Fos expression was examined after oral and peripheral administration of KKT in rats. Electrophysiological change of Oxt neurons and Oxt release upon application of KKT were measured in rat brain slice. The direct effect of KKT, its ingredients and its chemical components were examined by cytosolic $\mathrm{Ca}^{2+}\left(\left[\mathrm{Ca}^{2+}\right]_{i}\right)$ measurement in Oxt neurons and OTR-expressing HEK293 cells. Both intraperitoneal and oral administration of KKT in rats induced c-Fos expression in neurons of the paraventricular nucleus (PVN) including Oxt neurons. Application of KKT induced activation of Oxt neurons and Oxt release. KKT increased [Ca $\left.{ }^{2+}\right]_{i}$ in OTRexpressing HEK293 cells, and failed to activate with OTR antagonist. KKT-induced PVN Oxt neuron activation was also attenuated by OTR antagonist. Seven chemical components (rutin, ursolic acid, (Z)-butylidenephtalide, $p$-cymene, senkunolide, [6]-shogaol, [8]-shogaol) of three ingredients (Zizyphi Fructus, Angelicae Acutilobae Radix, Zingiberis Rhizoma) from KKT had potential to activate OTR. KKT can directly activate PVN Oxt neurons by interacting with OTR. The interaction of seven chemical components from KKT may contribute to activate OTR. Effect of KKT on Oxt neurons and OTR may contribute to the treatment of Oxt related disorders.
\end{abstract}

Keywords: Kamikihito, Oxytocin neuron, Oxytocin receptor, Traditional Japanese medicine

\section{Introduction}

$\mathrm{O}$ xytocin (Oxt) is a neuropeptide known to have important peripheral actions, such as the contraction of the uterus during labor and milk ejection [1]. Oxt is produced in the hypothalamus, mainly in the paraventricular nucleus (PVN) and supraoptic nucleus (SON), and is released within the central nervous system or circulation through the body via the posterior pituitary gland. Recent studies have revealed that in the brain, Oxt is considered to be involved in mood control and psychological stress adaptation [2-4]. Genetic deletion of Oxt in rodents was reported to increase anxiety-like behavior, which was reversed by Oxt treatment [5]. In humans, polymorphism of the Oxt receptor (OTR) has been reported to be associated with stress vulnerability [6], and epigenetic alteration of the OTR gene caused by stress in early life was found to be related to psychological malfunction [7]. We have also shown in the past that Oxt can treat metabolic syndrome and obesity in mice [8-10]. In addition to this, plasma Oxt levels are known to decrease with age and are considered to

Received 6 August 2020; revised 4 January 2021; accepted 23 July 2021.

Available online 15 December 2021.

* Corresponding author. Fax: 81245485643.

** Corresponding author. Fax: 81245485643.

E-mail addresses: maejimay@fmu.ac.jp (Y. Maejima), shimomur@fmu.ac.jp (K. Shimomura). 
be related to the pathogenesis of sarcopenia and osteoporosis [11,12]. Importantly, application of Oxt is reported to contribute to the recovery of muscle regeneration and osteoporosis as well.

Recently, external application of Oxt to the central nervous system (CNS) through nasal spray was reported to be clinically effective in treating patients with neuropsychological disorders such as autism and obesity [9-11,13-15].

As the external application of Oxt is effective, a drug that induces secretion of endogenous Oxt from Oxt neurons in the hypothalamus would be effective in the treatment of neuropsychological disorders. Although such a drug is very much expected, it is as yet to be discovered.

Kamikihito (KKT), a traditional Japanese (Kampo/ herbal) medicine composed of 14 crude drugs, is clinically used in Japan for the treatment of neuropsychological stress disorders including neurosis, amnesia, and insomnia [16]. As Oxt and KKT have common clinical effects, it is possible that KKT has an effect on Oxt neuron or OTR positive cells. Here, we analysed the effect of KKT on Oxt neurons in the hypothalamus and OTR expressing cells. We found that KKT can directly activate PVN Oxt neurons by interacting with OTR. We further elucidated seven chemical components of three ingredients from KKT that induce PVN Oxt neuron activation.

\section{Materials and methods}

\subsection{Animals}

8- to 10-week old Male Wistar rats, transgenic rats expressing Oxt-monomeric red fluorescent protein 1 fusion gene (Oxt-mRFP rats) [17] aged 6 weeks, and
Abbreviations
KKT Kamikihito
Oxt Oxytocin
OTR Oxytocin receptor
PVN paraventricular nucleus

10-week old male OTR-Venus mice [18] were used in this study. The animals were kept on a 12-h light/ dark cycle and given conventional food (CE-2; Clea, Osaka, Japan) and water ad libitum in individual cages. The lights were turned on at 07:00 am and turned off at 19:00. All experimental procedure and care of animals were carried out according to relevant guidelines and regulations and approved by Fukushima Medical University Institute of Animal Care and Use Committee.

\subsection{Reagents}

KKT, Hochuekkito (HE), Shikunshito (SKS) and Ninjinto (NJ) were kindly provided by Tsumura \& Co (Tokyo, Japan). These Kampo medicines were manufactured under strict scientific and quality control, and approved for ethical clinical use by the Ministry of Health, Labor, and Welfare of Japan. KKT comprises 14 herbal medicines in fixed proportions (see Table 1). KKT, HE, SKS and NJ were prepared as spray-dried powders from hot-water extracts. For in vitro studies, these Kampo medicines were dissolved in an experimental solution and, after centrifugation at $3000 \mathrm{rpm}$ for $5 \mathrm{~min}$, the supernatant was filtrated and used. For animal studies, KKT was orally administered or intraperitoneal (ip) injected to rats, as described below.

Table 1. Crude drugs in KKT, Hochuekkito, Shikunshito, Ninjinto.

\begin{tabular}{|c|c|c|c|}
\hline KKT & Hochuekkito & Shikunshito & Ninjinto \\
\hline Astragali Radix & Astragali Radix & & \\
\hline Ginseng Radix & Ginseng Radix & Ginseng Radix & Ginseng Radix \\
\hline Zizyphi Fructus & Zizyphi Fructus & Zizyphi Fructus & \\
\hline Angelicae Acutilobae Radix & Angelicae Acutilobae Radix & & \\
\hline $\begin{array}{l}\text { Zingibeiis Rhizoma } \\
\text { Polygalae Radix }\end{array}$ & Zingibeiis Rhizoma & Zingibei is Rhizoma & \\
\hline $\begin{array}{l}\text { Atractylodis Lanceae Rhizoma } \\
\text { Saussweae Radix } \\
\text { Gardenia Fructus } \\
\text { Longan Aiillus }\end{array}$ & Atractylodis Lanceae Rhizoma & Atractylodis Lanceae Rhizoma & Atractylodis Lanceae Rhizoma \\
\hline $\begin{array}{l}\text { Buplewi Radix } \\
\text { Zizyphi Semen }\end{array}$ & Buplewi Radix & & \\
\hline $\begin{array}{l}\text { Glycyrrhizae Radix } \\
\text { Poria }\end{array}$ & Glycyirhizae Radix & $\begin{array}{l}\text { Glycyirhizae Radix } \\
\text { Poria }\end{array}$ & Glycyirhizae Radix \\
\hline & $\begin{array}{l}\text { Citii Unshiu Pericarpium } \\
\text { Cimicifugae Rhizoma }\end{array}$ & & \\
\hline
\end{tabular}


Table 2. Chemical components of Zizyphi Fructus, Angelicas Acutilobae Radix and Zingiberis Rhizoma.

\begin{tabular}{|c|c|c|c|}
\hline Ingredients & Chemical components & Concentrations & References \\
\hline Zizyphi & Rutin & $0.8-8 \mu \mathrm{M}$ & {$[56]$} \\
\hline \multirow[t]{5}{*}{ Fructus } & Ursolic acid & $\begin{array}{l}0.05-2 \mu \mathrm{g} / \mathrm{mL} \\
(0.1-4.4 \mu \mathrm{M}))\end{array}$ & {$[57,58]$} \\
\hline & Scopoletin & N/A & \\
\hline & Jujubeside A & $1-25 \mu \mathrm{M}$ & [59] \\
\hline & Jujubeside B & $0.1-100 \mu \mathrm{M}$ & [60] \\
\hline & Betulinic acid & $5 \mu \mathrm{M}$ & [61] \\
\hline Angelicas & (r)-butylidenephthalide & $10-50 \mu \mathrm{M}$ & [62] \\
\hline Acutilobae & Bergapten & $2.5-100 \mu \mathrm{M}$ & [63] \\
\hline \multirow[t]{8}{*}{ Radix } & Umbeliferone & N/A & \\
\hline & Xanthotoxin & $25-100 \mu \mathrm{M}$ & [64] \\
\hline & $p$-Cymene & $50-250 \mu \mathrm{M}$ & [65] \\
\hline & $\beta$-Cytosterol & N/A & \\
\hline & Senkyunolide $\mathrm{H}$ & $6.25-100 \mu \mathrm{M}$ & [66] \\
\hline & Senkyunolide A & $\begin{array}{l}13-80 \mu \mathrm{g} / \mathrm{mL} \\
(68.3-420 \mathrm{nM})\end{array}$ & [67] \\
\hline & Falcarinfiol & $5-25 \mu \mathrm{M}$ & [68] \\
\hline & Levistolide A & $12.5-100 \mu \mathrm{M}$ & [69] \\
\hline Zingiberis & [6]-gingerol & $1-10 \mu \mathrm{M}$ & [70] \\
\hline \multirow[t]{6}{*}{ Rhizoma } & [8]-gingerol & $10 \mu \mathrm{M}$ & [71] \\
\hline & [10]-gingerol & $5-200 \mu \mathrm{M}$ & [72] \\
\hline & Zingerone & $5-15 \mu \mathrm{M}$ & [73] \\
\hline & [6]-shogaol & $1-10 \mu \mathrm{M}$ & {$[70]$} \\
\hline & [6]-paradol & $\begin{array}{l}1-20 \mathrm{mg} / \mathrm{mL} \\
(3.7-74.5 \mu \mathrm{M})\end{array}$ & [74] \\
\hline & [8]-shogaol & $10-50 \mu \mathrm{M}$ & [75] \\
\hline
\end{tabular}

Concentrations means the used concentration in vitro experiment in the each reference indicate right.

N/A: Scopletin and Umberifelone failed to measure $\left[\mathrm{Ca}^{2+}\right]$ i due to toxicity by interaction of excitation light.

N/A: There were no previous reports (in vitro) about $\beta$-Cytosterol.

Six chemical components of Zizyphi Fructus (ZF), ten chemical components of Angelicae Acutilobae Radix $(A R)$ and seven chemical components of Zingiberis Rhizoma $(Z R)$ were provided by Tsumura \& Co (Tokyo, Japan) and listed in Table 2. These chemical components were dissolved in DMSO or ethanol and used after over 1:1000-1:10000 dilution.

\subsection{Immunostaining of c-Fos after KKT administration}

Twenty-two male Wistar rats were used in this experiment. The rats kept in individual cages were habituated for 10 days. On the experiment day, food was removed at 09:00, and oral or ip administration of KKT was performed at 11:00. The KKT for oral administration was dissolved in distilled water, and the dose and concentration was $500 \mathrm{mg} / \mathrm{kg} / 5 \mathrm{~mL}$. KKT for ip administration was dissolved in saline and centrifuged for $20 \mathrm{~min}$ at $3000 \mathrm{rpm}$, and the obtained supernatant was then filtered. The dose and concentration of KKT for ip administration was
$500 \mathrm{mg} / \mathrm{kg} / 10 \mathrm{~mL}$. The dose of KKT was decided based on the prior studies on effects of KKT $(200-2000 \mathrm{mg} / \mathrm{kg}$ oral administration in mice or rats) [19-22].

Two hours after injection, the rats were deeply anesthetized by a mixture of three types of anesthetic agents $(5 \mathrm{~mL} / \mathrm{kg}$ ) (composed of $\alpha 2$ adrenaline receptor agonist (medetomidine), GABAA receptor agonist (midazolam), and opioid $\kappa$ receptor agonist (butorphanol)) and, perfused with 4\% PFA containing $0.2 \%$ picric acid. Then, $40-\mu \mathrm{m}$-thick brain sections were cut using a freezing microtome. Sections at $160 \mu \mathrm{m}$ intervals between -1.3 and $-2.1 \mathrm{~mm}$ from the bregma were used for c-Fos immunostaining. C-Fos staining was performed similar with the previous article [23]. Briefly, sections were rinsed in phosphate buffered saline (PBS: $0.01 \mathrm{M}$, $\mathrm{pH}$ 7.4) and incubated for 20 min with $0.3 \% \mathrm{H}_{2} \mathrm{O}_{2}$. Then, sections were incubated in PBS containing $0.3 \%$ Triton- $X, 2 \%$ normal goat serum (Cat\# 005-000121; Jackson Laboratories Inc. PA) and 2\% bovine serum albumin (Cat\# B2064, Sigma Aldrich, CA) (BSA) and then incubated with rabbit anti-c-Fos polyclonal IgG (Cat\# sc-52; Santa Cruz, CA; 1:5000) $[8,23]$ overnight at $4{ }^{\circ} \mathrm{C}$. Subsequently, sections were washed in PBS and incubated with biotinylated goat anti-rabbit polyclonal IgG (Cat\# BA-1000; Vector Laboratories Inc., CA; 1:500), and then with avidinbiotin complex (Cat\# PK-6100; ABC kit; Vector Laboratories Inc., CA). Immunoreactions were visualized by incubation in a $0.02 \%$ diaminobenzidine solution containing $0.3 \%$ nickel ammonium and $0.015 \% \mathrm{H}_{2} \mathrm{O}_{2}$ for $5 \mathrm{~min}$. The number of c-Fos-positive cells per section was counted for PVN (5-6 sections/rats) and SON (4-5 sections/ rats) under light microscope. The average of c-Fos in these sections are treated as individual data.

For double immunostaining of c-Fos and Oxt, cFos staining was performed in the similar methods as described above except immunoreactions were visualized by incubation in a $0.02 \%$ diaminobenzidine solution containing $2 \%$ nickel ammonium and $0.015 \% \quad \mathrm{H}_{2} \mathrm{O}_{2}$ for $5 \mathrm{~min}$. After washing, the sections were incubated with rabbit anti-oxytocin polyclonal IgG (Cat\# 20068; Immunostar Inc., WI; 1:5000) [24] for overnight at $4{ }^{\circ} \mathrm{C}$. Subsequently, sections were washed in PBS and incubated in PBS containing $2 \%$ normal goat serum (Cat\# 005-000-121; Jackson Laboratories Inc. PA) and 2\% BSA (Cat\# B2064, Sigma Aldrich, CA), and incubated with biotinylated goat anti-rabbit polycolonal IgG (Cat\# BA-1000; Vector Laboratories Inc., CA; 1:500). Then sections were incubated with 
avidin-biotin complex (Cat\# PK-6100; ABC kit; Vector Laboratories Inc., CA). Immunoreactions were visualized by incubation in a $0.02 \%$ diaminobenzidine solution containing $0.015 \% \mathrm{H}_{2} \mathrm{O}_{2}$ for $5 \mathrm{~min}$. The number of c-Fos-positive cells, Oxt positive cells and double positive cells per section were counted for PVN (5-6 sections/rats) and SON (4-5 sections/rats) under light microscope. The average of c-Fos in these sections are treated as individual data.

\subsection{Preparation of single PVN neurons and measurement of $\left[\mathrm{Ca}^{2+}\right]_{i}$ and subsequent immunocytochemistry in single neurons}

Nine male Wistar rats were used in this experiment. Single neurons were prepared from the PVN by using papain, accordingly to the previous report [8]. Cytosolic $\mathrm{Ca}^{2+}$ concentration $\left(\left[\mathrm{Ca}^{2+}\right]_{i}\right)$ was measured by ratiometric fura- 2 microfluorometry combined with digital imaging, as previously reported [8]. Briefly, prepared single neurons on a glass-bottom dish were incubated with $2 \mathrm{mM}$ fura2/AM (Dojin chemical, Kumamoto, Japan) for $30 \mathrm{~min}$ at room temperature, placed in a chamber, and superfused with $\mathrm{KRB}$ at $1 \mathrm{~mL} / \mathrm{min}$ at $30{ }^{\circ} \mathrm{C}$. Cells loaded with fluorescent dye were illuminated by alternating 340 and $380 \mathrm{~nm}$, and the resultant fluorescent images were captured. The ratio (F340/ F380) images were produced by Aquacosmos version 2.6 (Hamamatsu Photonics, Hamamatsu, Japan). The concentrations of KKT in the present study $(5-50 \mu \mathrm{g} / \mathrm{mL})$ for $\left[\mathrm{Ca}^{2+}\right]_{i}$ measurements in single neurons were based on the prior studies $(0.01-10 \mu \mathrm{g} / \mathrm{mL})[19,20]$. Therefore, the concentrations of $Z F, A R$ and $Z R$ were also set at $5-50 \mu \mathrm{g} / \mathrm{mL}$, accordingly to concentrations used for KKT.

After the $\left[\mathrm{Ca}^{2+}\right]_{i}$ measurements, single neurons were fixed in $4 \%$ PFA overnight. For immunocytochemistry, staining was carried out as previously reported [8]. Briefly, cells were incubated for $20 \mathrm{~min}$ with PBS containing $0.3 \% \mathrm{H}_{2} \mathrm{O}_{2}$. Then, sections were incubated in PBS containing 2\% normal goat serum (Cat\# 005-000-121; Jackson Laboratories Inc. PA) and 2\% BSA (Cat\# B2064, Sigma Aldrich, CA) and then incubated with rabbit anti-oxytocin polyclonal IgG (Cat\# 20068; Immunostar Inc., WI; 1:5000) for overnight at $4{ }^{\circ} \mathrm{C}$. Subsequently, cells were washed in PBS and incubated with biotinylated goat anti-rabbit polyclonal IgG (Cat\# BA1000; Vector Laboratories Inc., CA; 1:500), and then with avidin-biotin complex (Cat\# PK-6100; $\mathrm{ABC}$ kit; Vector Laboratories Inc., $\mathrm{CA}$ ). Immuno reactions were visualized by incubation in a $0.02 \%$ diaminobenzidine solution containing $0.015 \% \mathrm{H}_{2} \mathrm{O}_{2}$ for $5 \mathrm{~min}$.

\subsection{Criteria for $\left[\mathrm{Ca}^{2+}\right]_{i}$ responses}

Amplitudes of $\left[\mathrm{Ca}^{2+}\right]_{i}$ responses to agents were calculated by subtracting the prestimulatory basal $\left[\mathrm{Ca}^{2+}\right]_{i}$ ratio from the peak $\left[\mathrm{Ca}^{2+}\right]_{i}$ ratio. When increases in $\left[\mathrm{Ca}^{2+}\right]_{i}$ took place within $5 \mathrm{~min}$ after the addition of agents, and their amplitudes were 0.4 or larger, they were considered responses. For calculation of $0 \mathrm{mg} / \mathrm{mL}$ of $K K T, Z F, A R$ and $Z R$, basal $\left[\mathrm{Ca}^{2+}\right]_{\mathrm{i}}$ ratio from peak $\left[\mathrm{Ca}^{2+}\right]_{i}$ ratio for $5 \mathrm{~min}$ within $10 \mathrm{~min}$ from onset of measurement was analysed.

To combine individual $\left[\mathrm{Ca}^{2+}\right]_{i}$ imaging with immunocytochemical data, at the end of $\left[\mathrm{Ca}^{2+}\right]_{i}$ imaging, we took photographs of the cell in which $\left[\mathrm{Ca}^{2+}\right]_{i}$ was recorded and correlated $\left[\mathrm{Ca}^{2+}\right]_{i}$ data with immunocytochemical results.

\subsection{Electrophysiology}

Coronal brain slices $(300 \mu \mathrm{m})$ containing the PVN were prepared from transgenic rats expressing Oxtmonomeric red fluorescent protein (Oxt-mRFP rats). Seven male Oxt-mRFP rats were used in this experiment. All electrophysiological experiments were performed as previously described [25]. KKT, $\mathrm{HE}$, SKS and NJ were prepared as solution of $500 \mu \mathrm{g} / \mathrm{mL}$. The concentrations of KKT $(500 \mu \mathrm{g} / \mathrm{mL})$ for patch clamp in brain slice were decided based on the concentration of KKT used in single neurons $(5-50 \mu \mathrm{g} / \mathrm{mL})$. The concentration of KKT in brain slice patch clamp was set 10 times higher than concentration of KKT used for $\left[\mathrm{Ca}^{2+}\right]_{i}$ measurement in single neurons. Thus, the concentration of $\mathrm{HE}$, SKS and NJ were also set at similar concentration (500 $\mu \mathrm{g} / \mathrm{mL}$ ). OTR inhibitor, H4928 (BACHEM, Bubendorf, Switzerland) was applied at $10^{-7} \mathrm{M}$. The concentration of $\mathrm{H} 4928\left(10^{-7} \mathrm{M}\right)$ was decided based on the previous study [8].

\subsection{Measurement of oxytocin secretion from PVN slices}

Eighteen male Wistar rats were used in this experiment. The measurement of oxytocin from PVN was performed accordingly to previous reports $[8,25]$. Briefly, Wistar rats aged eight weeks were deeply anesthetized by a mixture of three types of anesthetic agents, decapitated, and their brains were removed. Three $400 \mu \mathrm{m}$ thick slices were prepared using a vibrating microtome, and the PVN-containing area was punched out. 
These processes were performed in a buffer composed of (in $\mathrm{mM}$ ) 229 mannitol, $3 \mathrm{KCl}, 26$ $\mathrm{NaHCO}_{3}, 1 \mathrm{H}_{3} \mathrm{PO}_{4}, 0.5 \mathrm{CaCl}_{2}, 7 \mathrm{MgCl}_{2}, 7$ glucose, and 1 kynurenate at $\mathrm{pH} 7.4$ with $95 \% \mathrm{O}_{2}$ and $5 \%$ $\mathrm{CO}_{2}$ mixed gas.

Prepared PVN slices were incubated at $37{ }^{\circ} \mathrm{C}$ for $30 \mathrm{~min}$ in artificial cerebrospinal fluid (aCSF) composed of (in mM) $126 \mathrm{NaCl}, 3 \mathrm{KCl}, 26 \mathrm{NaHCO}_{3}$, $1 \mathrm{H}_{3} \mathrm{PO}_{4}, 2 \mathrm{CaCl}_{2}$ and $1 \mathrm{MgSO}_{4}$ at $\mathrm{pH} 7.4$, with $95 \%$ $\mathrm{O}_{2}$ and $5 \% \mathrm{CO}_{2}$ mixed gas for recovery. Next, the PVN slices were incubated in aCSF with or without KKT $(500 \mu \mathrm{g} / \mathrm{mL})$ for $1 \mathrm{~h}$. The concentrations of KKT $(500 \mu \mathrm{g} / \mathrm{mL})$ for Oxt secretion from brain slice were decided based on the concentration of KKT used in brain slice patch clamp experiments $(500 \mu \mathrm{g} / \mathrm{mL})$. These incubations were performed in pairs (control and KKT). Secreted Oxt in the supernatant was determined using an oxytocin ELISA kit (Enzo Life Sciences) [10].

\subsection{Immunostaining of Oxt in OTR-Venus mice}

Three male OTR-Venus mice were deeply anesthetized by a mixture of three types of anesthetic agents, and perfused and $40-\mu \mathrm{m}$-thick brain sections were cut using a freezing microtome. PVN containing sections at $160 \mu \mathrm{m}$ intervals between -0.58 and $-1.22 \mathrm{~mm}$ from the bregma were used for Oxt immunostaining. The sections were incubated with in PBS containing $0.1 \%$ Triton- $X, 2 \%$ normal goat serum (Cat\# 005-000-121; Jackson Laboratories Inc. PA) and 2\% BSA (Cat\# B2064, Sigma Aldrich, CA), and then incubated with mouse anti-oxytocin monoclonal IgG (Cat\# MAB5296; Millipore, CA, 1:1000) [25] for overnight at $4{ }^{\circ} \mathrm{C}$, and incubated with Alexa flour 594-labelled goat anti-mouse IgG (Cat\# A11005; Life Technologies, CA, 1:400) for $30 \mathrm{~min}$. Fluorescence images of double positive of oxytocin and OTR were acquired by using a confocal laserscanning microscope (Fluoview FV10i; Olympus, Tokyo, Japan). Oxt, OTR and double-positive neurons were counted from these confocal images.

\subsection{Plasmid construct}

The mouse oxytocin receptor (mOTR) gene was amplified by using the primers 5'- ATA GGG AGA CCC AAG CTG GCT AGC GTT TAA ATG GAG GGC ACG CCC GCA GCC -3' and 5'- GCC AGT GAA TAA TTC TTC ACC TTT AGA CAT TGC CGA GGA TGG TTG AGA ACA -3'. The amplified DNA fragment was incorporated into the multicloning site in the pcDNA ${ }^{\mathrm{TM}} 3.1(+)$ plasmid by homogeneous recombination with primers 5'- ATG TCT AAA GGT GAA GAA TTA TTC ACT GGC -3' and 5'-
TTA AAC GCT AGC CAG CTT GGG TCT CCC TAT -3'. The RFP-encoding gene, which was kindly provided by Prof. Kazuto Kobayashi of Fukushima Medical University, was amplified with primers 5'CAG AGG AGC TGT TCT CAA CCA TCC TCG GCA ATG GTG TCT AAG GGC GAA GAG -3' and 5'-CGA GCG GCC GCC ACT GTG CTG GAT ATC TGC CTA ATT AAG TTT GTG CCC CAG-3'. The amplified fragment was incorporated into the Cterminus of the MOTR gene by homogeneous recombination with primers 5'- GCA GAT ATC CAG CAC AGT GGC GGC CGC TCG -3'and 5'TGC CGA GGA TGG TTG AGA ACA GCT CCT CTG -3'. Homogeneous recombination was performed by using the In-Fusion HD Cloning Kit (Takara Bio, Shiga, Japan).

\subsection{Transfection of OTR to HEK293 cells and measurement of $\left[\mathrm{Ca}^{2+}\right]_{i}$}

Cells were cultured in $35 \mathrm{~mm}$ a non-coated glassbottom dish with antibiotics $(0.5 \%(\mathrm{v} / \mathrm{v})$ penicillin/ streptomycin) in an incubator at $37{ }^{\circ} \mathrm{C}, 5 \% \mathrm{CO}_{2}$. When the cell confluency reached approximately $50-70 \%$ after $48 \mathrm{~h}$ incubation, $2.5 \mu \mathrm{g}$ of OTR plasmid DNA and $5.0 \mu \mathrm{L}$ of Lipofectamine2000 reagent were mixed and incubated for $10 \mathrm{~min}$ according to the manufacturer's instructions, and applied to the cells.

HEK293 cells, which were transfected with OTRRFP, were incubated with $2 \mathrm{mM}$ fura-2/AM (Dojin chemical, Kumamoto, Japan) for $30 \mathrm{~min}$ at room temperature, placed in a chamber and superfused with KRB containing $10 \mathrm{mM}$ glucose at $1 \mathrm{~mL} / \mathrm{min}$ at $30{ }^{\circ} \mathrm{C}$. The ratio (F340/F380) images were produced by an Aquacosmos version 2.6. These cells were applied Oxt (Peptide institute Inc. Osaka, Japan) $\left(10^{-9}-10^{-5} \mathrm{M}\right)$ or KKT $(0.5-75 \mu \mathrm{g} / \mathrm{mL})$. OTR inhibitor, $\mathrm{H} 4928\left(10^{-7} \mathrm{M}\right)$, was applied under treatment of Oxt or KKT. Amplitudes of $\left[\mathrm{Ca}^{2+}\right]_{\mathrm{i}}$ responses to each agent were calculated by subtracting the prestimulatory basal $\left[\mathrm{Ca}^{2+}\right]_{\mathrm{i}}$ ratio from the peak $\left[\mathrm{Ca}^{2+}\right]_{\mathrm{i}}$ ratio within $5 \mathrm{~min}$ after onset of agent application.

The concentration of Oxt used for the measurement of $\left[\mathrm{Ca}^{2+}\right]_{\mathrm{i}}$ responses in cultured HEK cells was decided based on the prior study $\left(10^{-11}-10^{-6} \mathrm{M}\right)$ [26]. The concentration of KKT in measurement of $\left[\mathrm{Ca}^{2+}\right]_{i}$ responses in cultured HEK cells was decided based on the results shown in Fig. $2 \mathrm{~d}-\mathrm{f}(5-50 \mu \mathrm{g} / \mathrm{mL})$. The concentration of $\mathrm{H} 4928\left(10^{-7} \mathrm{M}\right)$ was decided based on the previous study [8].

The OTR antagonizing experiment using H4928 with Oxt or KKT administrations, the concentrations of Oxt $\left(10^{-7} \mathrm{M}\right.$, which are enough dose to increase $\left[\mathrm{Ca}^{2+}\right]_{i}$ in OTR expressing HEK293 cells) and KKT 


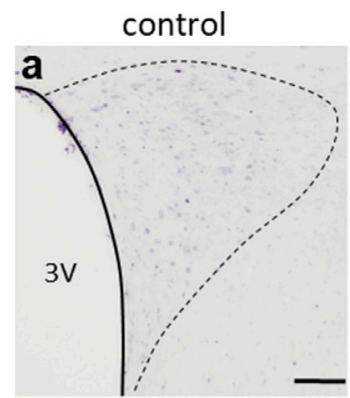

\section{oral KKT $500 \mathrm{mg} / \mathrm{kg}$}
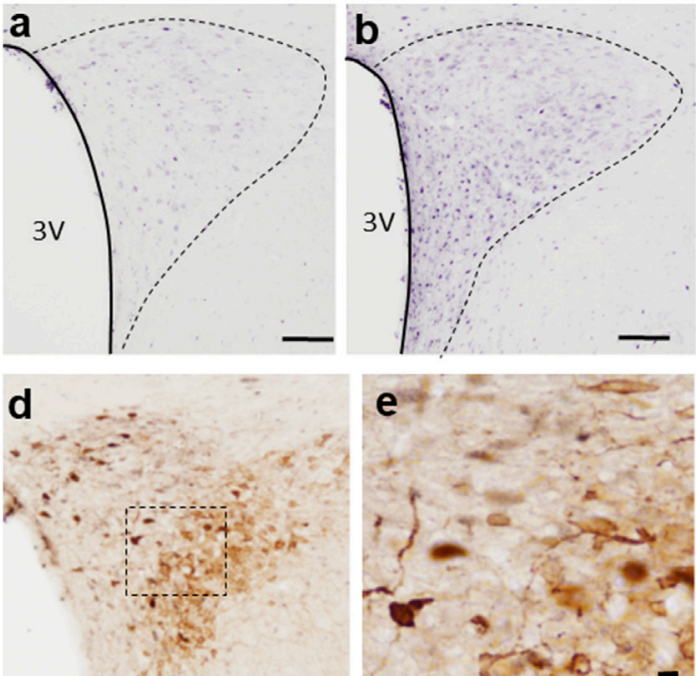

$$
\text { e }
$$
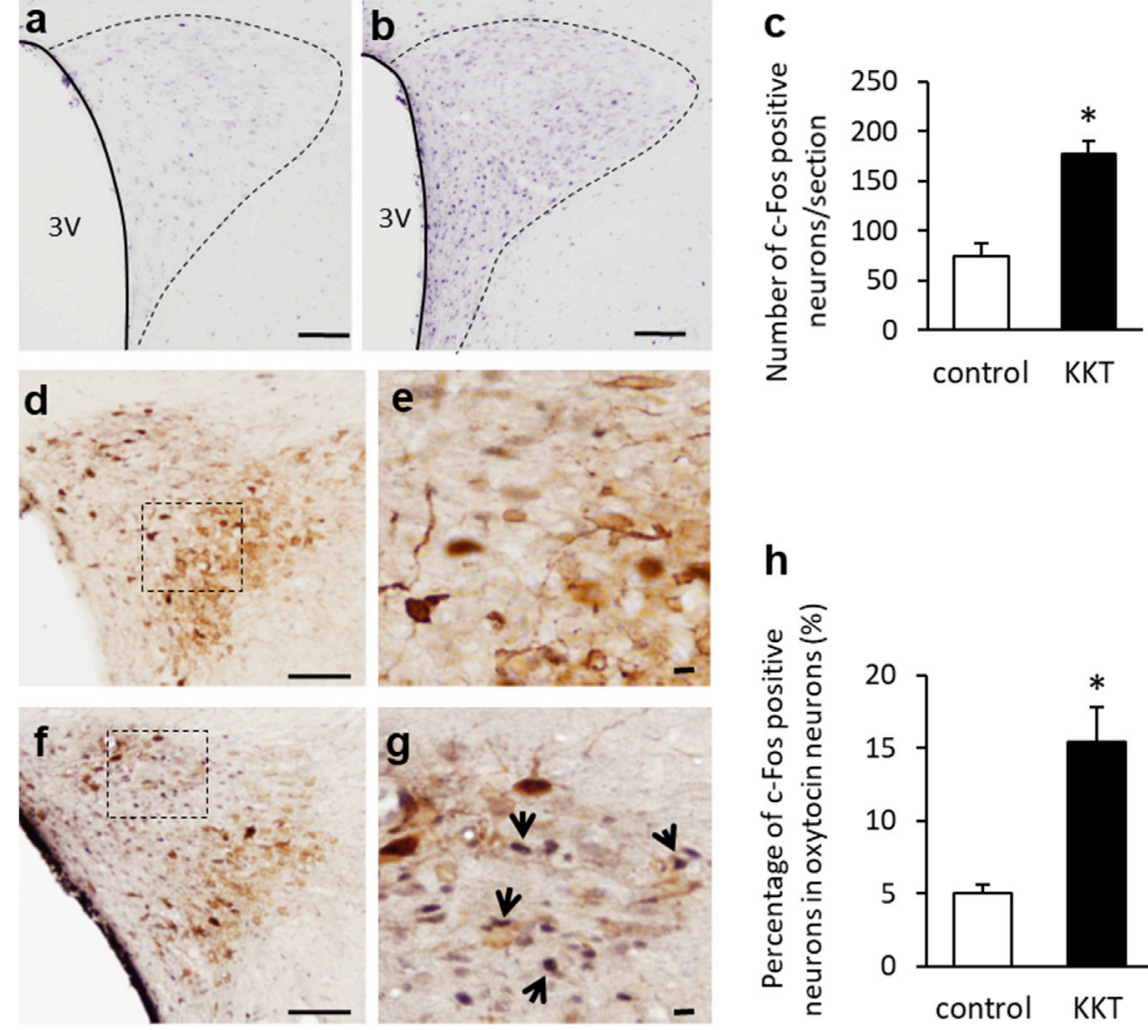

\section{h}
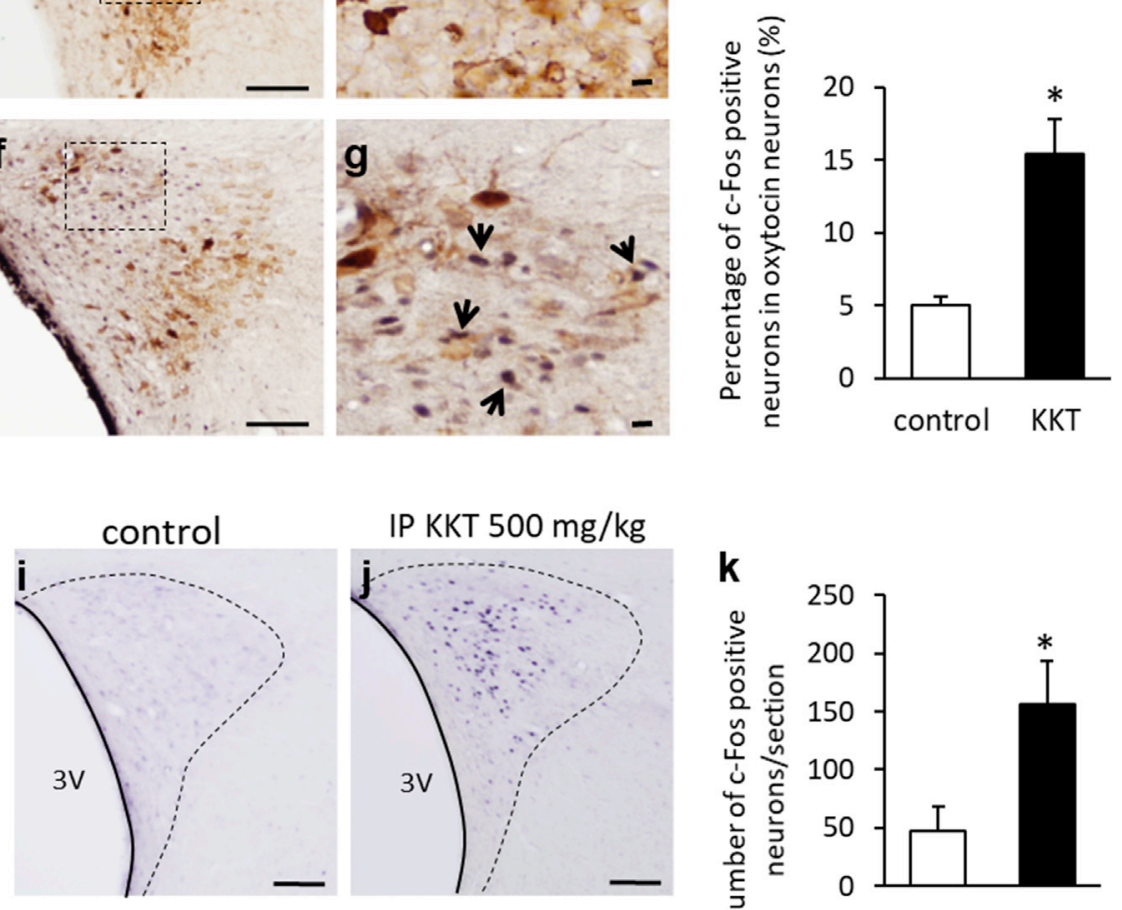

IP KKT $500 \mathrm{mg} / \mathrm{kg}$
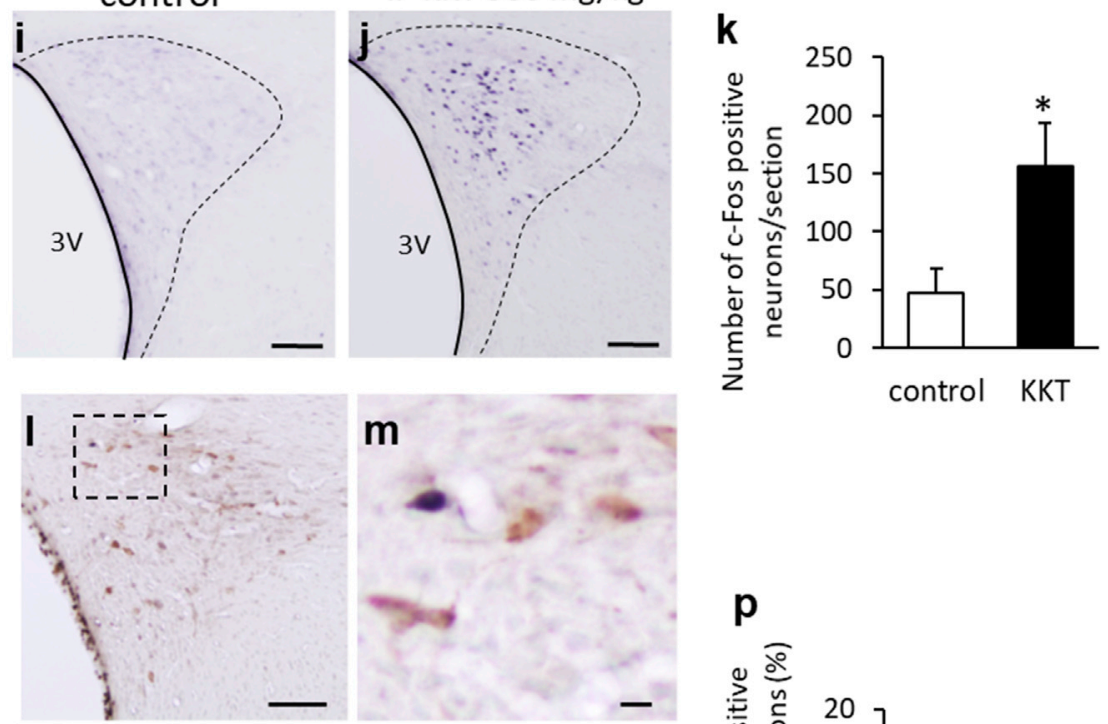

n

m
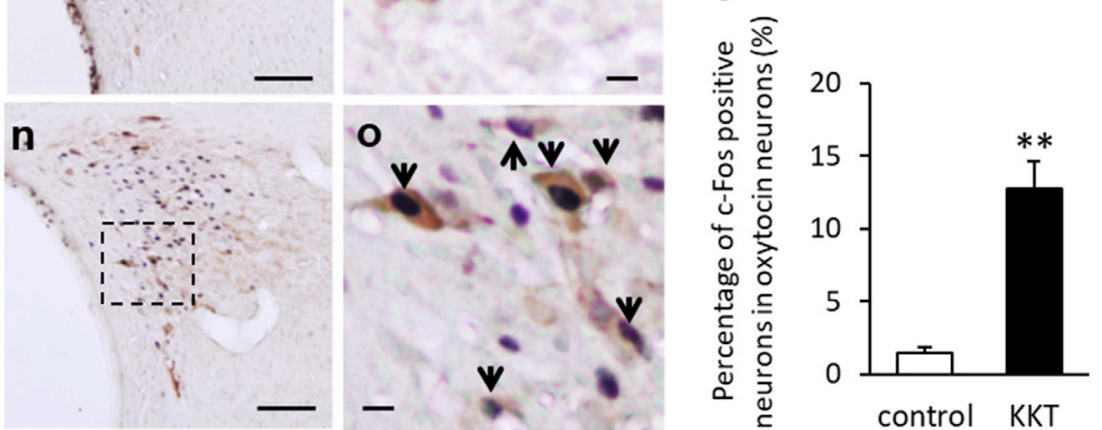
( $50 \mu \mathrm{g} / \mathrm{mL}$, which is the maximum dose to increase $\left[\mathrm{Ca}^{2+}\right]_{i}$ in OTR expressing HEK293 cells) were decided based on the results shown in Fig. 41 and q.

The concentrations of 21 chemical components of $Z F, A R$ and $Z R$ were also decided based on data provided by Tsumura \& Co. and the prior in vitro studies (Table 2). As shown in Table 2, these chemical components were used in ranges of $\mu \mathrm{M}$. Therefore, the concentrations of chemical components in $Z F, A R$ and $Z R$ are all used in concentration of $10 \mu \mathrm{M}$ in this study.

After measurement of $\left[\mathrm{Ca}^{2+}\right]_{j}$, the cells were fixed in $4 \%$ PFA for $2 \mathrm{~h}$. The cells were mounted on a cover glass with a mount medium with DAPI (Vector laboratories, CA). The confocal images were captured by FV10i (Olympus, Tokyo, Japan). The percentage of OTR expression was analysed from 15 areas $(200 \mu \mathrm{m} \times 200 \mu \mathrm{m} /$ area$)$ from three plates.

\subsection{Measurement of plasma concentrations of carvacrol and quercetin}

Three male wistar rats (aged 9 weeks) were used. Food was deprived at 19:00 before the day of experiment. On the experiment day, KKT $(500 \mathrm{mg} /$ $\mathrm{kg} / 5 \mathrm{~mL}$ ) was orally administered at 9:00. Blood samples were collected from tail vein into potassium EDTA-treated tubes (BD Microtainer ${ }^{\circledR}$ blood collection tubes, Becton Dickinson, Tokyo, Japan) before oral administration ( $0 \mathrm{~min})$, and at 20, 60 and $120 \mathrm{~min}$ after oral administration. Blood samples were centrifuged at 10,000 $\mathrm{g}$ for $10 \mathrm{~min}$, and plasma samples were stored at $-80{ }^{\circ} \mathrm{C}$ until analysis.

Plasma concentrations of carvacrol and quercetin were determined using ultra-performance liquid chromatography (UPLC) system (Waters Corp., Milford, MA) with UV and fluorometric detection. Myricetin and thymol were used as internal standards (I.S.) for the quantification of quercetin and carvacrol, respectively. Sample preparation was performed using a Monolithic solid-phase extraction column (MonoSpin ${ }^{\circledR}$ C18, GL Sciences, Tokyo, Japan) according to the manufacturer's instruction with minor modifications. After filtration thorough a
$0.22 \mu \mathrm{m}$ membrane filter (Millex LG, Millipore), $10 \mu \mathrm{L}$ of the sample solution was injected to the UPLC system. The mobile phase consisted of $0.2 \%$ formic acid (A) and acetonitrile (B), and chromatographic separation was achieved on an AQCUITY BEH Shield RP18 column (particle size $1.7 \mu \mathrm{m}$; $2.1 \mathrm{~mm} \times 50 \mathrm{~mm}$, Waters) at $40{ }^{\circ} \mathrm{C}$ using gradient elution with a flow rate of $0.6 \mathrm{~mL} / \mathrm{min}$. The gradient program for carvacrol determination was set as follows: $0-4.0 \mathrm{~min}, 30-40 \% \mathrm{~B} ; 4.0-5.0 \mathrm{~min}, 40-90 \%$ $\mathrm{B}$; and $5.0-8.0 \mathrm{~min}, 30 \% \mathrm{~B}$. The gradient program for quercetin determination was set as follows: 0-4.0 $\mathrm{min}, 10-30 \% \mathrm{~B} ; 4.0-5.0 \mathrm{~min}, 30-80 \% \mathrm{~B}$; and $5.0-8.0 \mathrm{~min}, 10 \% \mathrm{~B}$. Carvacrol was detected with the excitation wavelength set at $278 \mathrm{~nm}$ and the emission at $306 \mathrm{~nm}$. Quercetin was detected at $370 \mathrm{~nm}$. The limits of quantification for carvacrol and quercetin were $6 \mathrm{nM}$ and $3 \mathrm{nM}$, respectively. The mean intra- and inter-assay coefficients of variance $(\mathrm{CV})$ for quercetin were $9.9 \%$ and $2.3 \%$, respectively. The mean intra- and inter-assay CVs for carvacrol were $4.9 \%$ and $5.2 \%$, respectively. The accuracies for quercetin and carvacrol were $100 \pm 0.6 \%$ and $100 \pm 6.6 \%$, respectively. Typical chromatograms of quercetin and carvacrol with the respective I.S. were shown in Fig. 9b.

\subsection{Statistical analysis}

All data are presented as mean \pm SEM. Numbers for every experiment (group) are given in the figure legends and refer to the number of every individual mouse in the respective group.

Animals used for c-Fos expression after ip or oral KKT treatment (Fig. 1), were randomly divided into two group. Animal and cells were given to experimenter lacking the information regarding conditions of cells or treatment done to rats in order to make experimenter blind to treatment or condition. All data were not treated as technical replicates, treated as independent values.

For statistical analysis, GraphPad Prism 7.0 (GraphPad Software, San Diego, USA) were used. After ANOVA, post hoc test were only performed if

Fig. 1. c-Fos expression in the PVN after oral or intraperitoneal (ip) administration of KKT. $a, b$ : c-Fos expression after oral administration of distilled water (a) or KKT $(500 \mathrm{mg} / \mathrm{kg})$ in the PVN (b). 3V: third ventricle. c: Number of c-Fos-positive neurons per section in the PVN $(n=6,6) . d-g$ : Double staining of $c$-Fos and Oxt after oral distilled water $(d, e)$ or $K K T(f, g)$. e and $g$ indicate the enlarged image of the dotted area in $d$ and $f$, respectively. Arrows indicate c-Fos and Oxt double-positive neurons. $h$ : The percentage of c-Fos-positive neurons among Oxt neurons (n=6, 6). Scale bars in $a, b, d, f=100 \mu m$. Scale bars in e, $g=10 \mu m * p<0.05$, unpaired $t$-test. $i, j: c$-Fos expression after ip administration of saline (i) or KKT (500 $m g / k g)$ in the PVN (j). 3V: third ventricle. $k$ : Number of c-Fos-positive neurons per section in the PVN $(n=5,5)$. $l-o$; Double staining of c-Fos and Oxt after ip saline $(l, m)$ or $K K T(n, o)$ administration. $m$ and o indicate the enlarged image of the dotted area in $l$ and $n$, respectively. Arrows indicate $c$-Fos and Oxt double-positive neurons. $p$ : The percentage of c-Fos-positive neurons among Oxt neurons $(n=5,5)$. Scale bars in $i, j, l, n=100 \mu m$. Scale bars in $m, o=10 \mu m * * p<0.01$, unpaired t-test. 
a

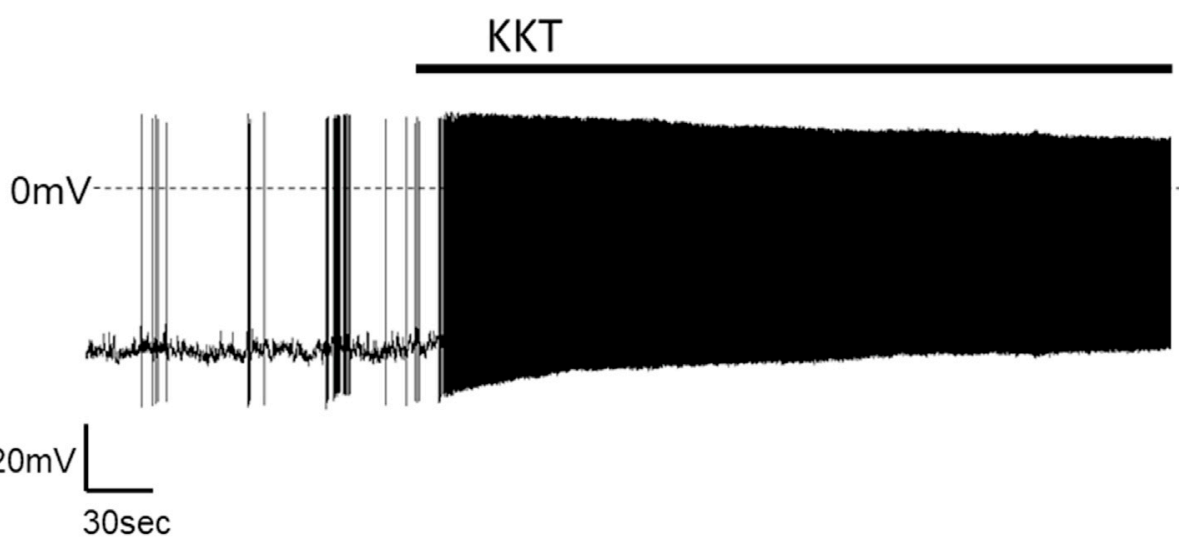

b
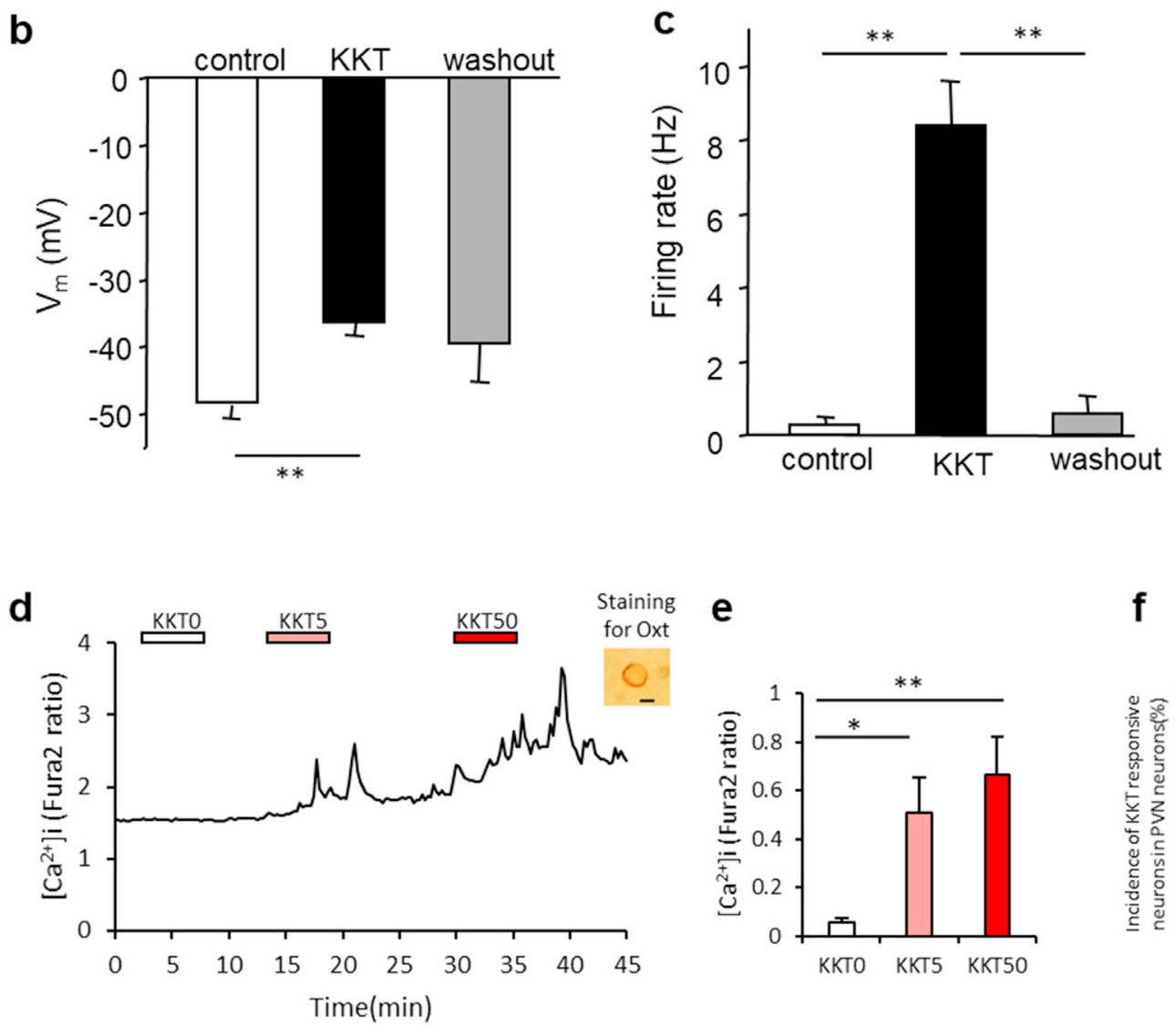

e

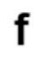

g
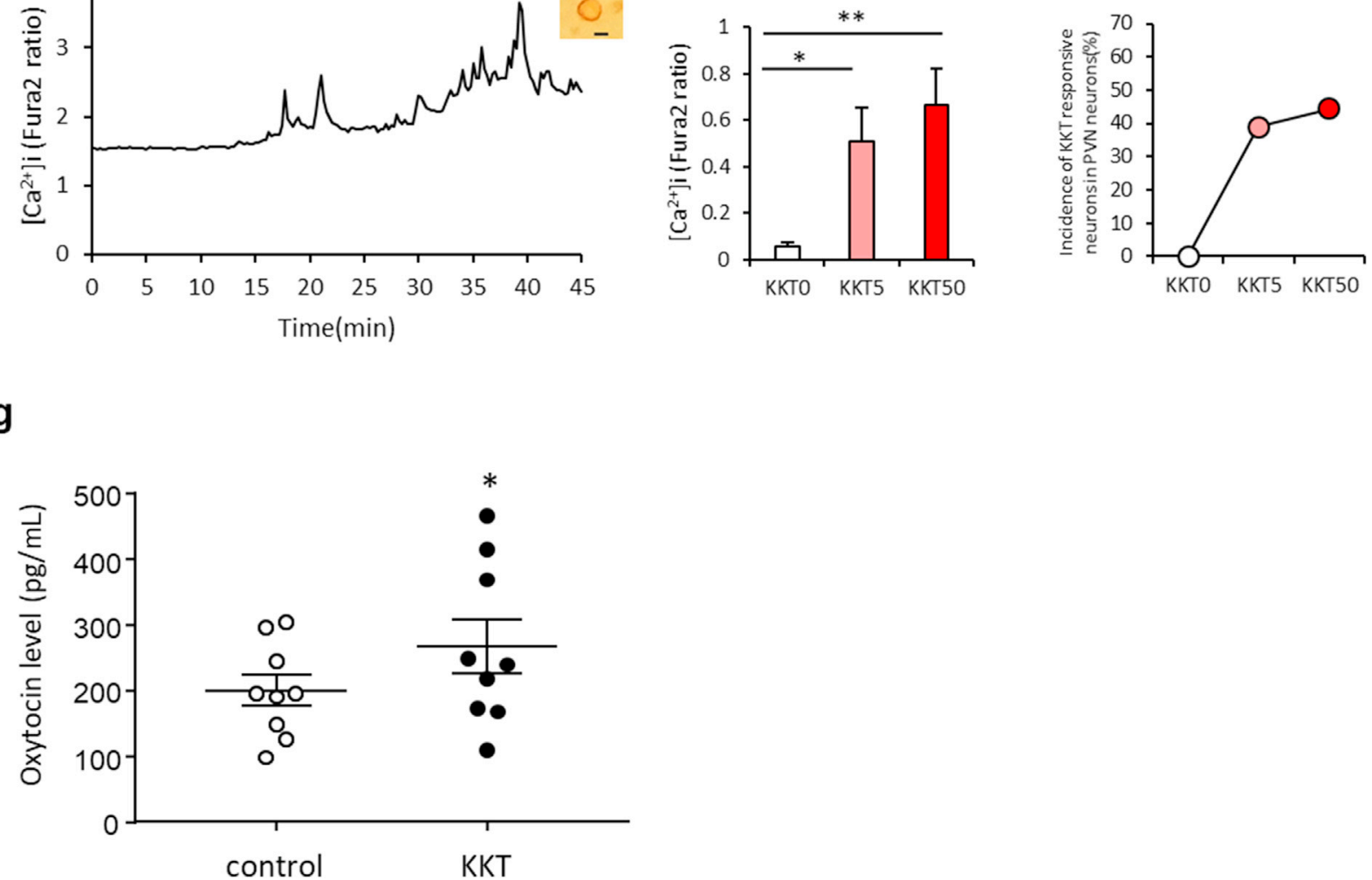

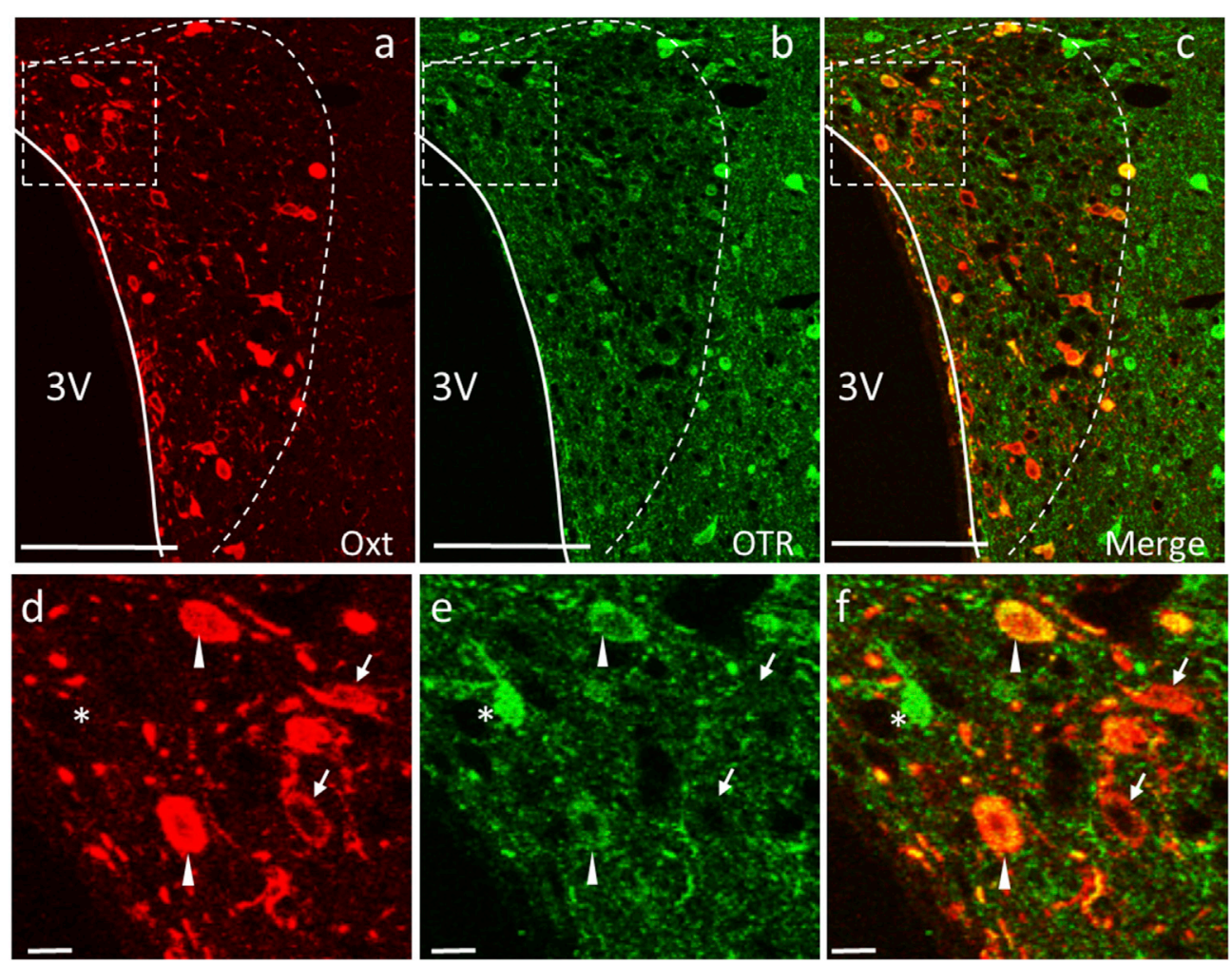

Fig. 3. Co-localization of Oxt and OTR in the PVN. a-c: Confocal images of Oxt (a), OTR (b) and merged image of a and $b$ (c). $3 V$ : third ventricle. Scale bars $=100 \mu \mathrm{m} . d-f:$ Enlarged image of the dotted area in a-c, respectively. Scale bars $=10 \mu \mathrm{m}$. Arrow heads indicate representative Oxt and OTR double-positive neurons. Arrows indicate representative single Oxt immunoreactive neurons. Asterisk (*) indicates representative single OTR positive neurons.

$F$ had achieved the significance level of $p<0.05$. Differences are considered statistically significant when $p$-values are lower than 0.05 . Assessment of significance was only done for numbers $\geq 5$.

All data were analyzed without any transformation except the data from the effect of chemical components of $Z F, A R, Z R$ on measurements of $\left[\mathrm{Ca}^{2+}\right]_{i}$ in OTR-expressing HEK293 cells (Fig. 8). This is because in order to compare the effect of Oxt itself to each chemical components on OTR, we calculated ratio of average of $\left[\mathrm{Ca}^{2+}\right]_{i}$ treated with Oxt as "1". Thus, the data shown in Fig. 8 are presented as fold of control mean ratio. The differences in fold of control mean ratio between OTR(-) and OTR $(+)$ were analyzed using unpaired t-test. Concerning with sample size in experiment using cultured cells, sample size was decided based on the previous study [27]. Fujitsuka et al. measured $\left[\mathrm{Ca}^{2+}\right]_{\mathrm{i}}$ in $100 \%$ GHS-R expressing COS cells at $n=8-12$. In our experiment $46 \%$ HEK 293 cells were transfected OTR. Thus, it was estimated three times sample size were considered to be reliable. Therefore we decided to measure $\left[\mathrm{Ca}^{2+}\right]_{\mathrm{i}}$ at least $n>30$.

\section{Results}

\subsection{Induction of c-Fos expression by peripheral administration of KKT}

Oral administration of KKT $(500 \mathrm{mg} / \mathrm{kg})$ in rats induced c-Fos expression localized in the PVN (control: $74.6 \pm 12.8 /$ section, KKT: $177.9 \pm 13.1 /$ section, Fig. $1 \mathrm{a}-\mathrm{c})$. There were also significant differences in the number of c-Fos positive neurons in the SON

Fig. 2. Effects of KKT on the activation of PVN Oxt neurons and the release of Oxt. a: Representative recording of membrane potential from an identified Oxt neuron in Oxt-mRFP rat. b: Mean membrane potential (+SEM) before, during, and $5 \mathrm{~min}$ after $500 \mu \mathrm{g} / \mathrm{mL} \mathrm{KKT} \mathrm{washout}(n=5)$. c: Mean firing frequency (+SEM) before (control), during, and 5 min after $500 \mu \mathrm{g} / \mathrm{mL}$ KKT washout $(n=5) . * * p<0.01$, one-way ANOVA followed by Tukey's multiple range test. d: Representative cytosolic $\mathrm{Ca}^{2+}\left(\left[\mathrm{Ca}^{2+}\right]_{i}\right)$ chart upon absence of KKT (KKT0), $5 \mu \mathrm{g} / \mathrm{mL}$ (KKT5) and 50 $\mu \mathrm{g} / \mathrm{mL}$ (KKT50) treatment in the single neuron of Oxt. Scale bar $=10 \mu \mathrm{m}$. e: Amplitude of $\left(\left[\mathrm{Ca}^{2+}\right]_{i}\right)$ in each dose of KKT-responsive neurons in the PVN. * $p<0.05$, one-way ANOVA followed by Tukey's multiple range test. $f$ : Incidence of KKT-responsive neurons in PVN neurons (\%). ( $n=18)$. g: Oxt concentration after incubation with or without KKT $(500 \mu \mathrm{g} / \mathrm{mL}) .(n=9,9) * p<0.05$, paired t-test. 


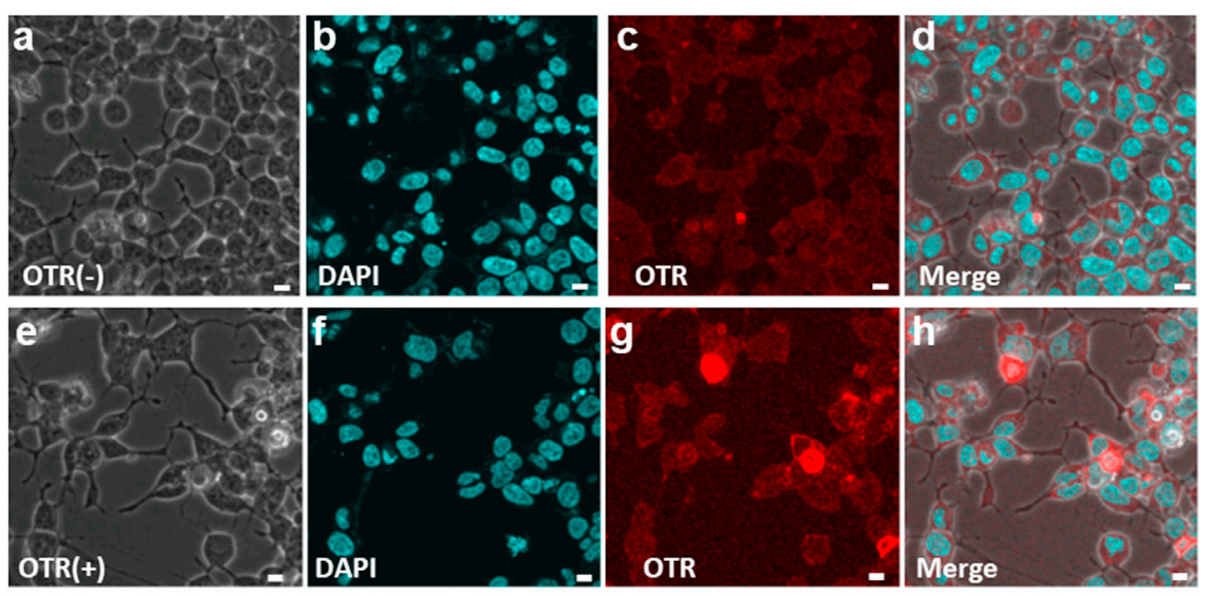

i
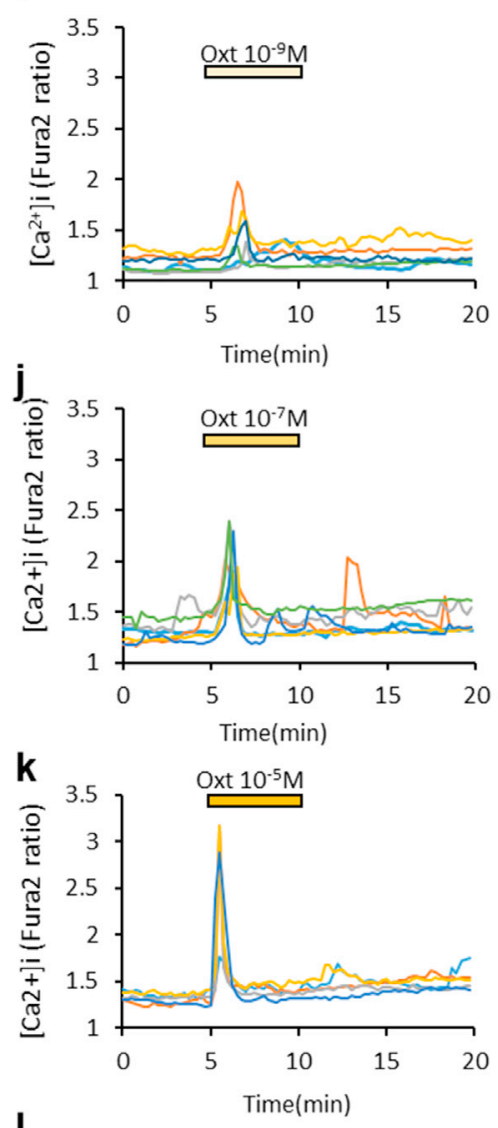

I

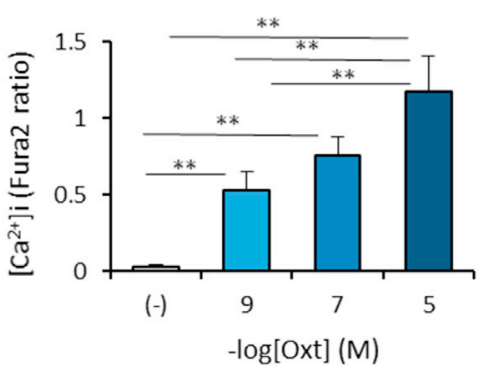

m
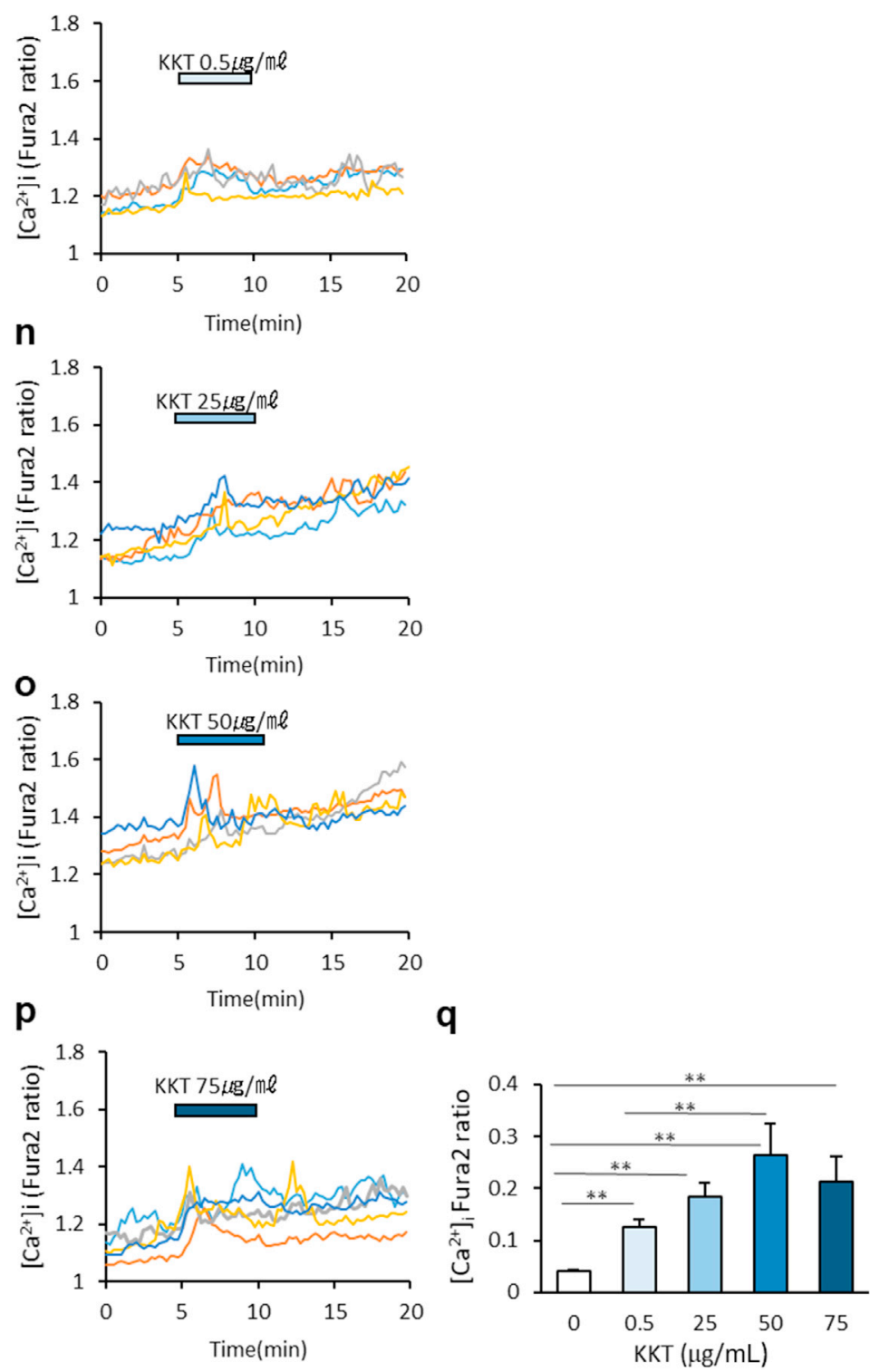
(control: $55.2 \pm 6.7 /$ section, KKT: $95.1 \pm 4.2 /$ section). The percentage of Oxt neurons among c-Fos positive neurons in the PVN were significantly higher in the KKT group $(15.4 \pm 2.4 \%)$ compared to the wateradministered control group $(5.0 \pm 0.6 \%)$ (Fig. $1 \mathrm{~d}-\mathrm{h}$ ).

It has been known that oral Kampo administration can change its state of ingredients by the gastrointestinal factors such as gastric digestion or gut flora. In order to examine weather activation of PVN neurons by KKT is induced by the components of KKT or by the gastrointestinal factors mediated end products, we performed i.p injection of KKT to skip the gastrointestinal factors. Similar results were obtained when the same dose of KKT was ip administered (Fig. 1i-k). The number of c-Fos positive neurons after ip injection of KKT in the PVN and SON were significantly higher (PVN: $156.8 \pm 36.5 /$ section, SON: $159.9 \pm 20.9 /$ section) compared with the saline-injected control (PVN: $47.2 \pm 20.6$ /section, SON: $30.2 \pm 14.5$ ). The percentage of Oxt neurons among c-Fos-positive neurons in the PVN were significantly higher in the KKT group $(12.8 \pm 1.8 \%)$ compared to the saline-administered control group $(1.4 \pm 0.4 \%)$ (Fig. $11-p)$. These results indicate that KKT can affect the PVN with both oral and ip administration, indicating that gastrointestinal factors such as gastric digestion or gut flora has only small effect if any.

\subsection{KKT directly activates PVN Oxt neurons with secretion of Oxt}

Application of $500 \mu \mathrm{g} / \mathrm{mL}$ KKT dramatically increased the electrical activity of identified Oxt neurons in the PVN from Oxt-mRFP rats (Fig. 2a). KKT significantly increased the membrane potential from a hyperpolarized $(-48.2 \pm 2.1 \mathrm{mV})$ to depolarized $(-36.3 \pm 2.3 \mathrm{mV})$ state $(n=5 ; p<0.01)$ (Fig. 2b). In parallel with the increase in the membrane potential, the action potential frequency increased from $0.3 \pm 0.2 \mathrm{~Hz}$ to $8.4 \pm 1.2 \mathrm{~Hz}(n=5$; $p<0.001$ ) (Fig. 2c). An increase in firing frequency was reversed after washing out KKT for $5 \mathrm{~min}$ $(0.6 \pm 0.5 \mathrm{~Hz}$ after washout; $n=5 ; p<0.001)$ (Fig. 2c).
To examine whether KKT had a direct effect on PVN Oxt neurons, we monitored $\left[\mathrm{Ca}^{2+}\right]_{i}$ levels in isolated single neurons. After finishing $\left[\mathrm{Ca}^{2+}\right]_{i}$ measurements, these neurons were stained immunocytochemically with a specific antiserum for Oxt. Administration of 5 and $50 \mu \mathrm{g} / \mathrm{mL}$ KKT to single PVN neurons increased $\left[\mathrm{Ca}^{2+}\right]_{i}$ (Fig. 2d) which neuron was subsequently shown to contain Oxt. The amplitude of $\left[\mathrm{Ca}^{2+}\right]_{i}$ (Fig. 2e) and the percentage of KKT responsive neurons (Fig. 2f) increased dose dependently. Seven $(38.9 \%)$, and eight $(44.4 \%)$ out of 18 neurons responded to $5 \mu \mathrm{g} / \mathrm{mL}$ and $50 \mu \mathrm{g} / \mathrm{mL}$ of KKT, respectively. Three out of eight (37.5\%) KKT $(50 \mu \mathrm{g} / \mathrm{mL})$-responsive neurons were identified as Oxt neurons.

Data from the electrophysiological experiment and $\left[\mathrm{Ca}^{2+}\right]_{i}$ imaging indicate that KKT directly acts on PVN neurons including Oxt neurons, and induces its activation.

Next, in order to see whether Oxt neuron activation by KKT is reflected in the secretion of Oxt, we measured the amount of secreted Oxt from brain slices containing PVN with and without KKT by using a batch incubation technique [25]. As shown in Fig. $2 \mathrm{~g}$, 1-h application of KKT $(500 \mu \mathrm{g} / \mathrm{mL})$ significantly increased the amount of secreted Oxt, indicating that activation of Oxt neurons by KKT is indeed reflected in Oxt secretion.

\subsection{OTR expression in the PVN Oxt neurons}

Taking the results of c-Fos expression after KKT administration (oral and ip) and measurement of $\left[\mathrm{Ca}^{2+}\right]_{i}$ under KKT application into consideration, we hypothesized that KKT may activate Oxt neurons through OTR expressed in the Oxt neurons. Therefore, we examined the colocalization of Oxt and OTR in the PVN. By staining Oxt immunologically in OTR-Venus mice, which express Venus fluorescent proteins in OTR-expressing neurons, abundant co-localization of Oxt and OTR in the neurons of the PVN were identified (Fig. 3). Further analysis showed that, $52.5 \pm 4.2 \%(696 / 1240$ cells $)$ of Oxt neurons expressed OTR.

Fig. 4. The effect of KKT on OTR-expressing HEK293 cells. $a-h$ : Representative confocal image of HEK293 cells with (e-h) or without (a-d) transfection of OTR. Among analysis of 2705 cells from 8 plate, $1248(46.1 \pm 3.6 \%)$ cell were found to be transfected. a, e indicate bright images. $b, f$ indicate DAPI nuclear staining. $c$, $g$ indicate OTR expressing cells. $d, h$ indicate merged images of $b$ and $c, f$ and $g$, respectively. Scale bars $=10 \mu m$. $i-k$ : Representative $\left[\mathrm{Ca}^{2+}\right]_{i}$ images upon applying $10^{-9} \mathrm{M}$ Oxt (i), $10^{-7} \mathrm{M}$ Oxt (j) and $10^{-5} \mathrm{M}$ Oxt ( $\mathrm{k}$ ). l: Mean amplitude of $\left[\mathrm{Ca}^{2+}\right]_{i}$ in each dose of Oxt. (-) indicate absence of Oxt (control). (Controln $=105,10^{-9} \mathrm{M} \mathrm{Oxt} n=35,10^{-7} \mathrm{M} \mathrm{Oxt} n=35,10^{-5} \mathrm{M} \mathrm{Oxt} n=35$ ). $\mathrm{m}_{-\mathrm{p}}$ : Representative $\left[\mathrm{Ca}{ }^{2+}\right]_{i}$ images upon applying KKT $0.5 \mu \mathrm{g} / \mathrm{mL}(\mathrm{m}), 25 \mu \mathrm{g} / \mathrm{mL}(\mathrm{n}), 50 \mu \mathrm{g} / \mathrm{mL}$ (o) and $75 \mu \mathrm{g} / \mathrm{mL}(\mathrm{p})$. q: Mean of $\left[\mathrm{Ca}^{2+}\right]_{i}$ amplitude in each dose of KKT. 0 indicates the absence of KKT (control). (Control $n=242,0.5 \mu \mathrm{g} / \mathrm{mL} n=72,25 \mu \mathrm{g} / \mathrm{mL} n=103,50 \mu \mathrm{g} / \mathrm{mL} n=33,75 \mu \mathrm{g} / \mathrm{mL} n=34$ ). **p $<0.01$, one-way ANOVA followed by Tukey's multiple range test. 
a

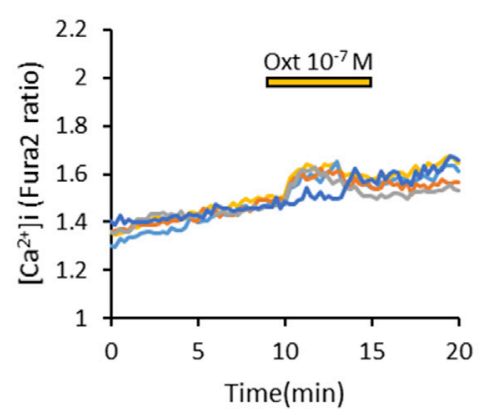

d

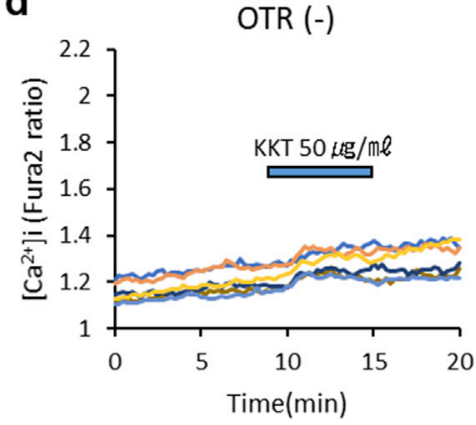

g

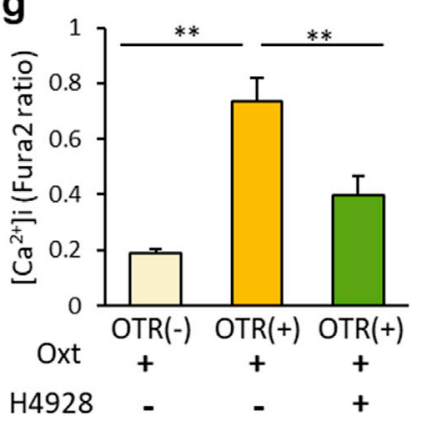

b $\quad$ OTR (+)

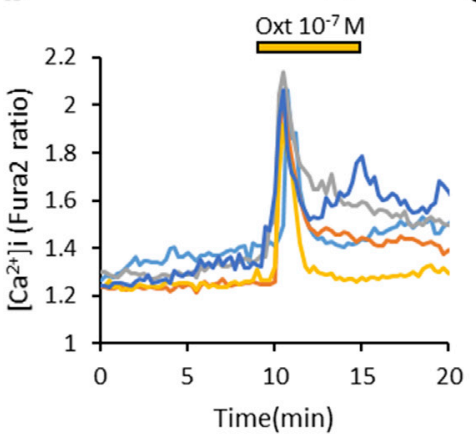

e

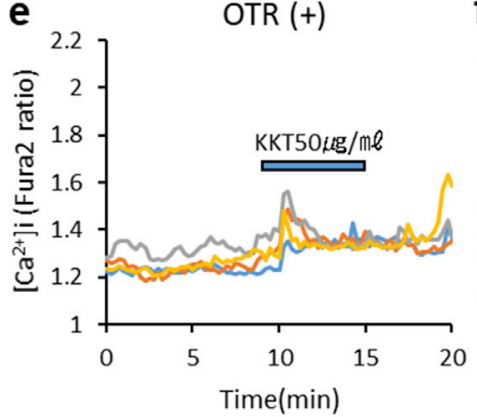

h

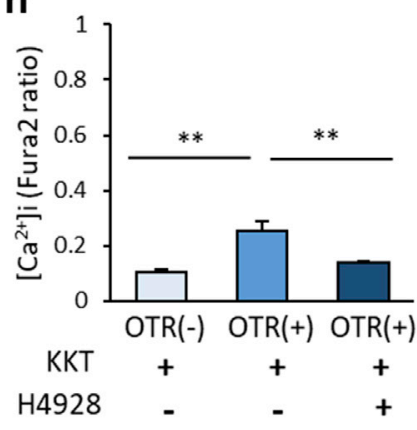

c
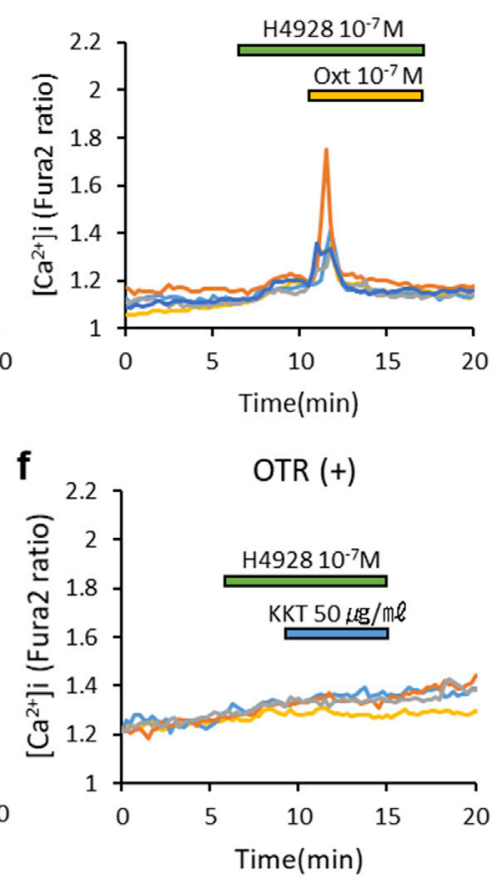

i

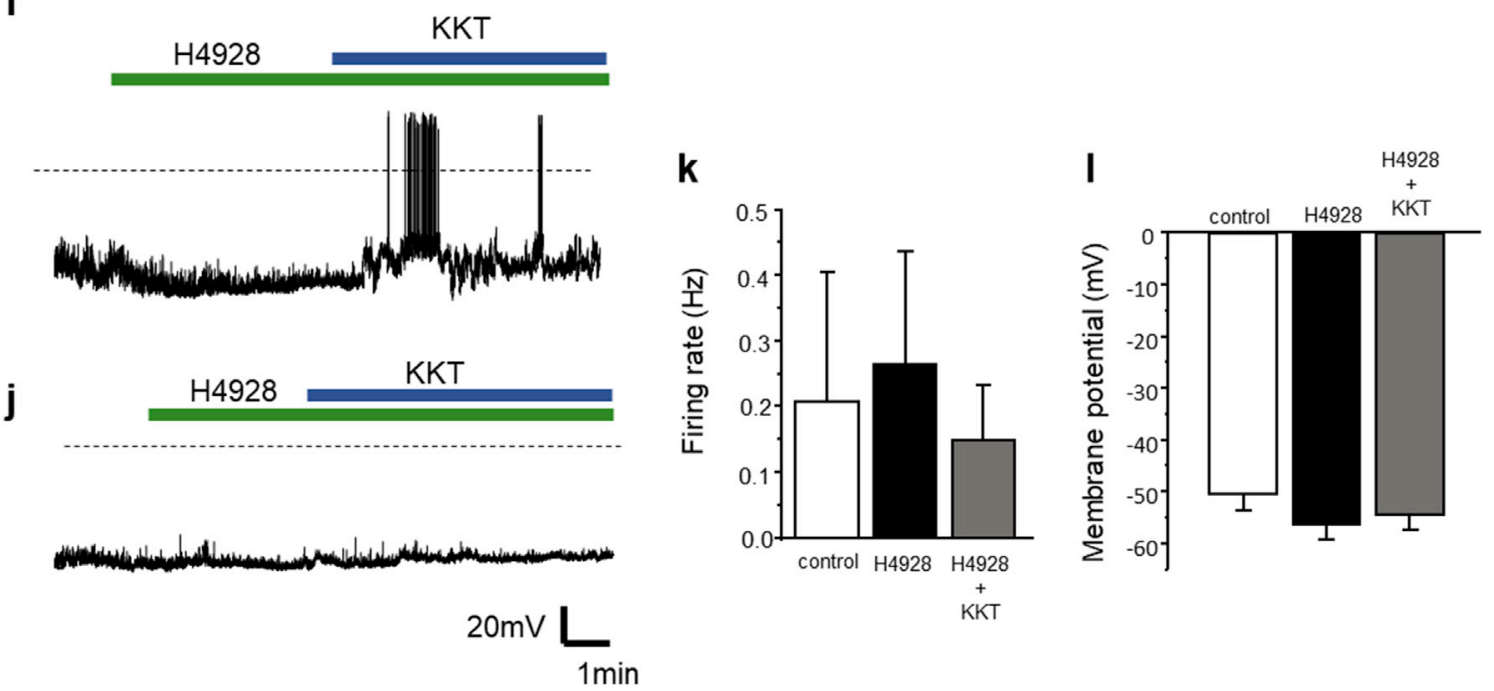

Fig. 5. The effect of OTR inhibitor on the effect of KKT in HEK293 cells and PVN Oxt neurons. a: Representative change of $\left[\mathrm{Ca}^{2+}\right]_{i}$ image applying with $10^{-7} \mathrm{M}$ Oxt in HEK293 cells, which was not transfected OTR. $b$, c: Representative change of $\left[\mathrm{Ca}^{2+}\right]_{i}$ image applied with $10^{-7} \mathrm{M}$ Oxt $(b)$ or $10^{-7} \mathrm{M}$ Oxt pre-treatment of $10^{-7} \mathrm{M} H 4928$ (c) in OTR-transfected HEK293 cells. d: Representative change of $\left[\mathrm{Ca}^{2+}\right]_{i}$ image applying with $50 \mu \mathrm{g} / \mathrm{mL} \mathrm{KKT}$ in 
a

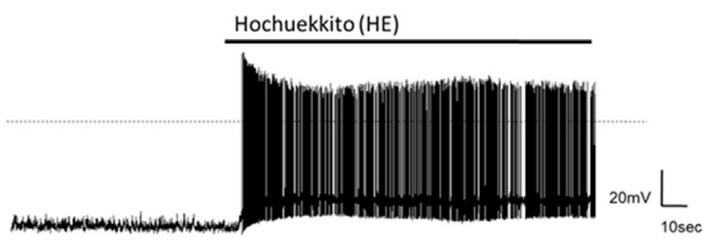

d

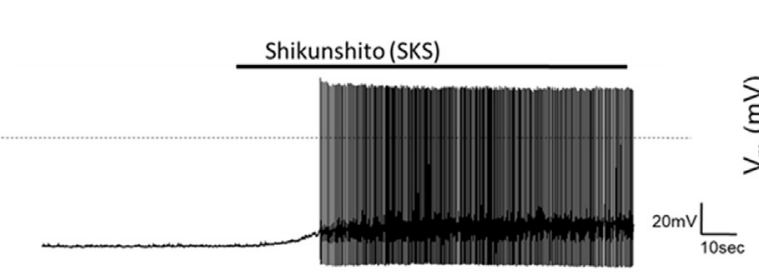

g

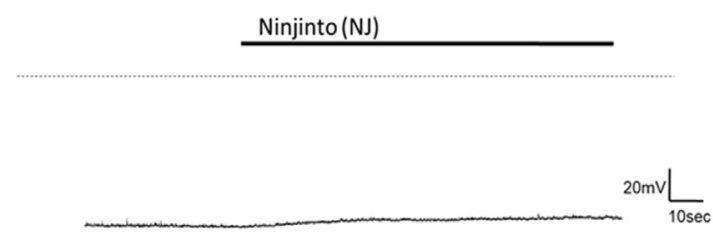

b

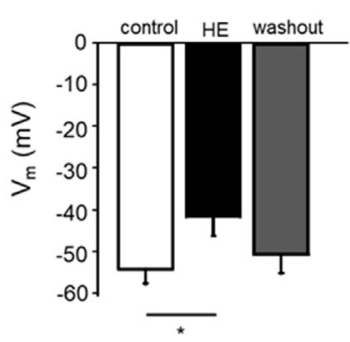

C

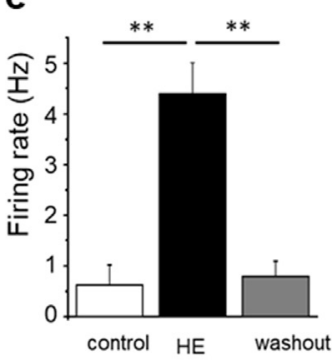

e

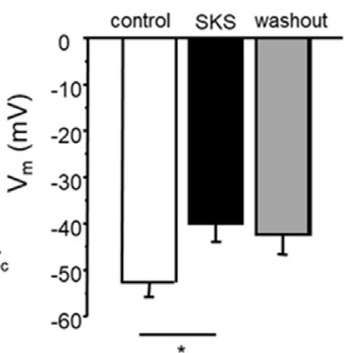

f

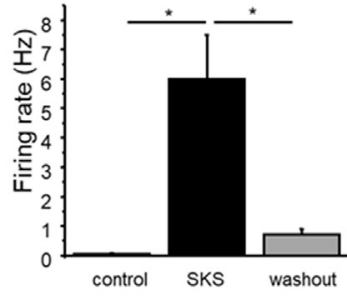

h

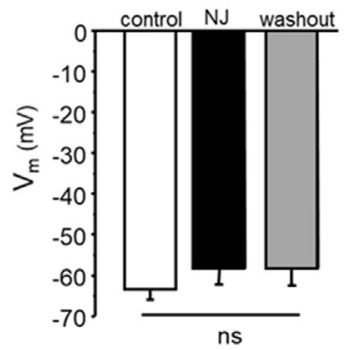

i

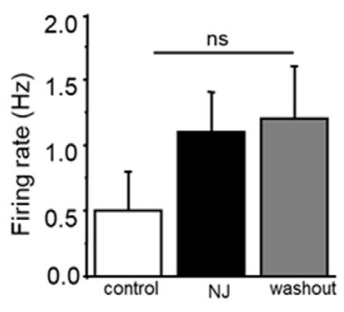

Fig. 6. The membrane potential and firing frequency under treatment of Hochuekkito (HE), Shikunshito (SKS) and Ninjinto (NJ). a, d, g: Representative recording of membrane potential under treatment of $H E(a), S K S(d)$ and $N J(g)$ from an identified Oxt neuron in Oxt-mRFP rat. b, $c, e$, $f, h, i$ : mean membrane potential (+SEM) $(b, e, h)$ and mean firing frequency (+SEM) $(c, f, i)$ before (control), during, and $5 \mathrm{~min}$ after $500 \mu \mathrm{g} / \mathrm{mL} \mathrm{HE}$ $(b, c, n=5)$, SKS (e, $f, n=5)$ and NJ $(h, i, n=5)$ washout. ${ }^{* *} p<0.01, * p<0.05$. one-way ANOVA followed by Tukey's multiple range test.

\subsection{KKT stimulates cells with OTR expression}

Since we found that $50 \%$ of PVN Oxt neurons express OTR, we examined the effect of KKT on OTRtransfected cultured cells. As shown in Fig. $4 a-h$, OTR was expressed in HEK293 cells, and we monitored $\left[\mathrm{Ca}^{2+}\right]_{i}$ levels upon application of KKT. As shown in Fig. 4i-1, HEK293 cells with OTR showed increase in $\left[\mathrm{Ca}^{2+}\right]_{\mathrm{i}}$ level upon application of $10^{-9} \mathrm{M}$ to $10^{-5} \mathrm{M}$ Oxt in a dose-dependent manner, indicating that the HEK293 cells with OTR expression that we used in this study were properly functional. We then applied KKT in these cells and measured the change in $\left[\mathrm{Ca}^{2+}\right]_{\mathrm{i}}$ level. The application of KKT from $0.5 \mu \mathrm{g} /$ $\mathrm{mL}$ to $50 \mu \mathrm{g} / \mathrm{mL}$ induced a dose-dependent increase in $\left[\mathrm{Ca}^{2+}\right]_{\mathrm{i}}$ level (Fig. $4 \mathrm{~m}-\mathrm{q}$ ). Because the application

HEK293 cells, which was not transfected OTR. $e$, f: Representative change of $\left[\mathrm{Ca}^{2+}\right]_{i}$ image applying with $50 \mu \mathrm{g} / \mathrm{mL} \mathrm{KKT}(\mathrm{e})$ or $50 \mu \mathrm{g} / \mathrm{mL} \mathrm{KKT}$ pretreatment of $10^{-7} \mathrm{M} \mathrm{H4928} \mathrm{(f)} \mathrm{in} \mathrm{OTR} \mathrm{transfected} \mathrm{HEK293} \mathrm{cells.} g$, $h$ : Mean of amplitude of $\left[\mathrm{Ca}^{2+}\right]_{i}$ in each cell and treatment. $(g ;$ from left bar, $n=91$, $104,49$. $h$; from left bar, $n=97,103,138)$. ${ }^{* *} p<0.01$, one-way ANOVA followed by Tukey multiple range test. $i$, j: Representative recording of membrane potential with application of $500 \mu \mathrm{g} / \mathrm{mL}$ KKT with pre-treatment of $10^{-7} \mathrm{M} H 4928$ in the Oxt neurons in Oxt-mRFP rat. Two from eight neurons exhibited slight action potentials, as shown in $i$, and six from eight exhibited no action potential, as shown in $j . k$, $l$ : Mean membrane potential (+SEM) and Mean firing frequency (+SEM) before (control), with H4928 and with both H4928 and KKT treatment $(n=8)$. 
a

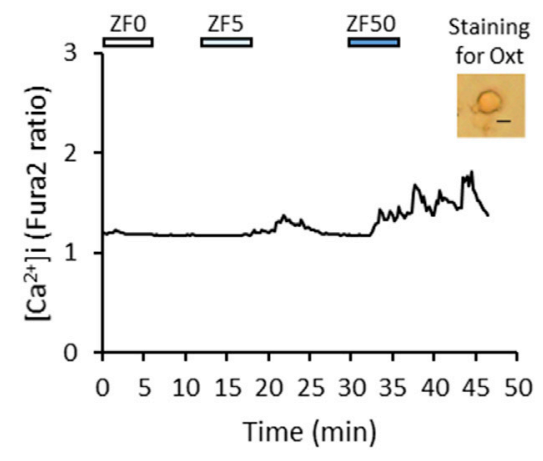

d

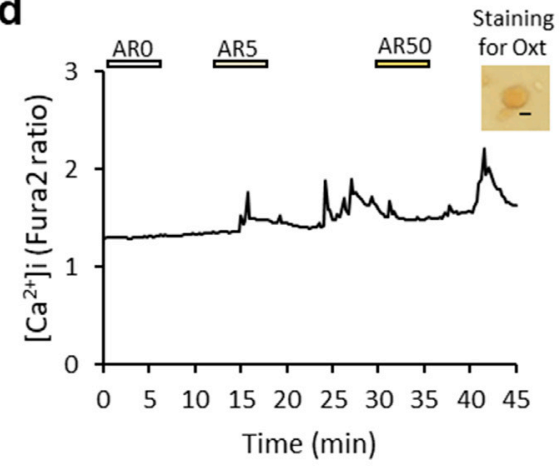

g

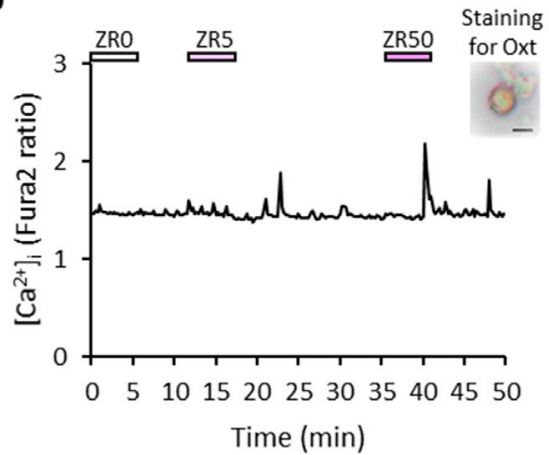

j

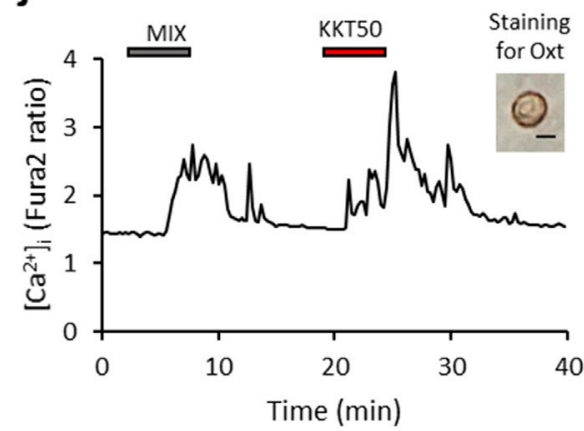

b
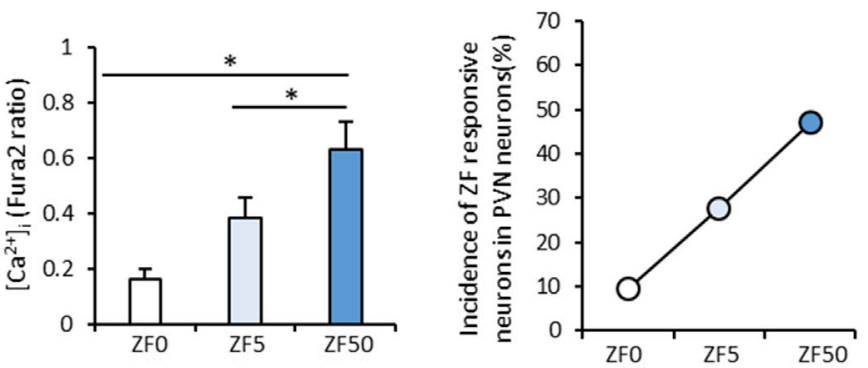

e

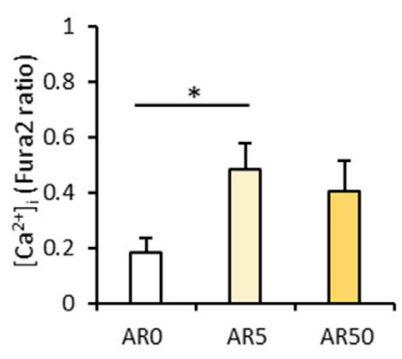

h
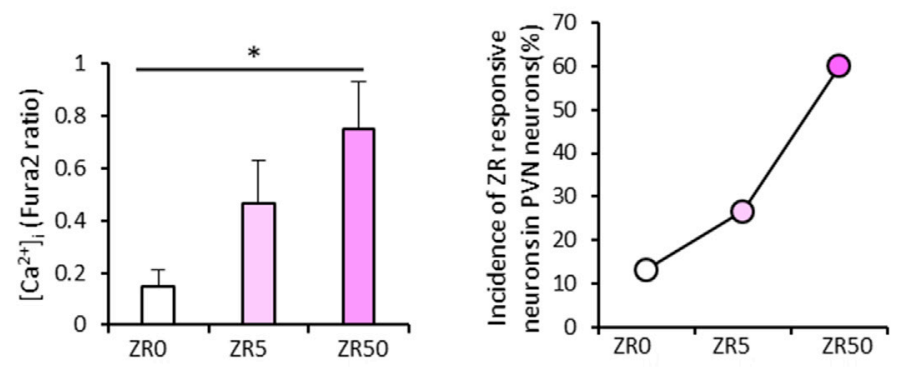

k

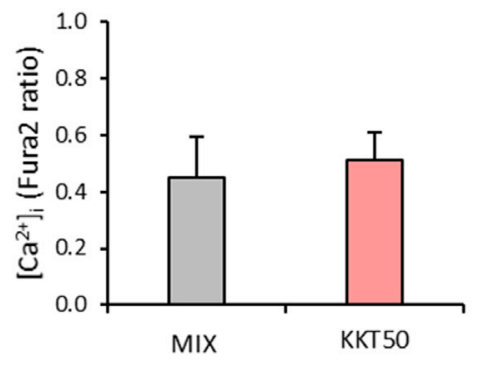

Fig. 7. The effect of Zizyphi Fructus (ZF), Angelicae Acutilobae Radix (AR), Zingiberis Rhizome (ZR) on $\left[\mathrm{Ca}^{2+}\right]_{i}$ in PVN Oxt neurons. $a, d, g$ : Representative $\left[\mathrm{Ca}^{2+}\right]_{i}$ image under treatment of $5 \mu \mathrm{g} / \mathrm{mL}$ (5) and $50 \mu \mathrm{g} / \mathrm{mL}$ (50) ZF (a), AR (d) and ZR (g) in Oxt neurons. $b, f$, i: Mean of amplitude of $\left[\mathrm{Ca}^{2+}\right]_{i}$ under treatment of $5 \mu \mathrm{g} / \mathrm{mL}$ (5) and $50 \mu \mathrm{g} / \mathrm{mL}(50) \mathrm{ZF}(b, n=83), A R(f, n=44)$ and $\mathrm{ZR}(i, n=15)$ measured in the PVN neurons. 0 indicates the basal control before treatment of each crude drug. ${ }^{*} p<0.05$, one-way ANOVA followed by Tukey's multiple range test. $b, e, h$ : The incidence of each dose of ZF- (c), AR- (f) and ZR- (i) responsive neurons in the PVN neurons. The criteria of responsive neurons were described in detail in the Methods section. $j$ : Representative $\left[\mathrm{Ca}^{2+}\right]_{i}$ image under treatment of $50 \mu \mathrm{g} / \mathrm{mL}$ ZF-AR-ZR mixture (MIX) and $50 \mu \mathrm{g} / \mathrm{mL}$ KKT in PVN Oxt neuron. $k$ : Mean of amplitude of $\left[\mathrm{Ca}^{2+}\right]_{i}$ under treatment of MIX and KKT $(n=16)$. There were no significant differences. Unpaired $t$-test. 
a

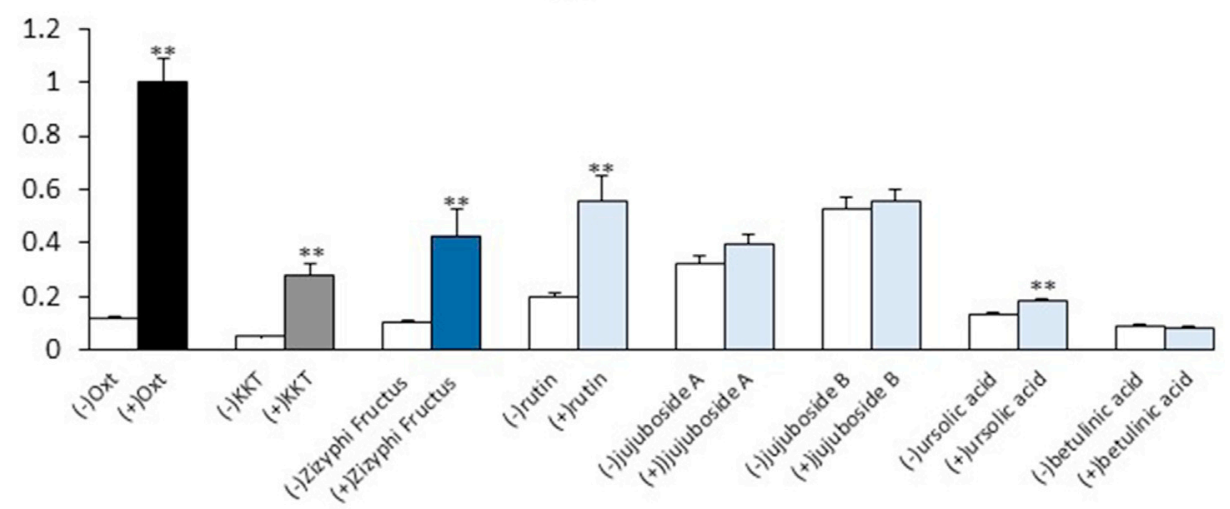

b

Angelicae Acutilobae Radix

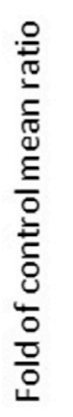

1.2

] 
a

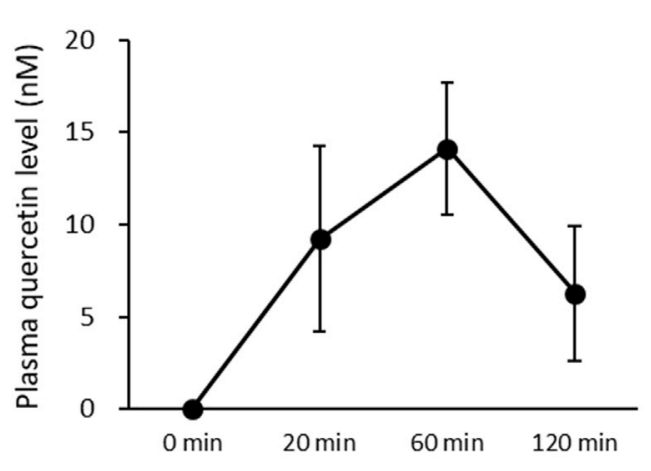

Time after oral KKT administration b
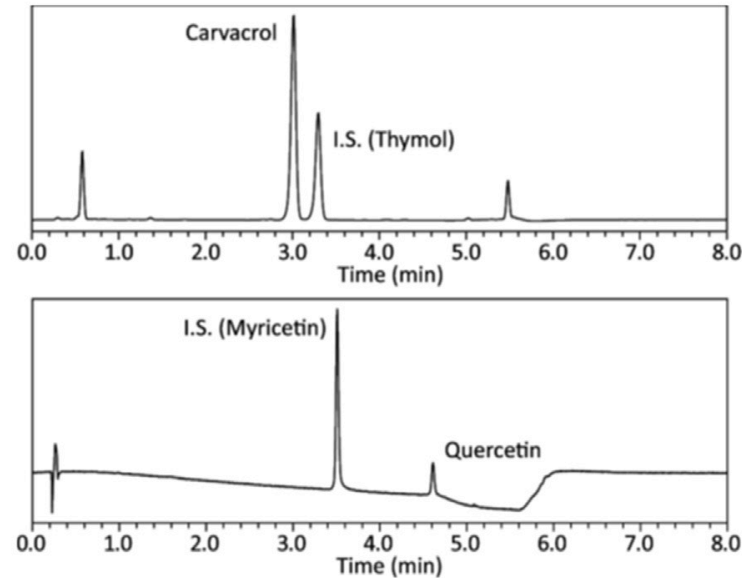

C

Oxt $10^{-7} \mathrm{M}$

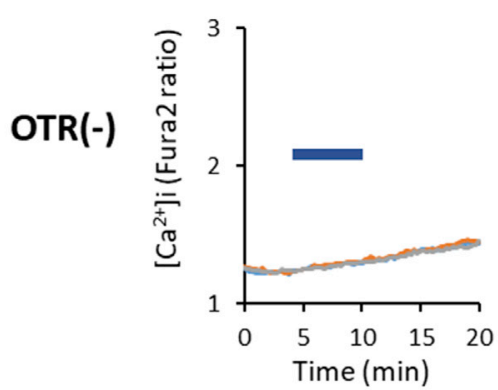

f

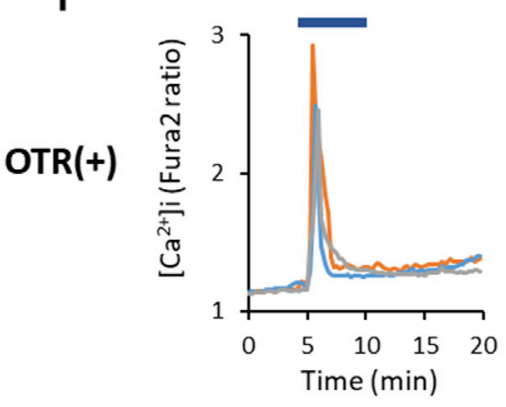

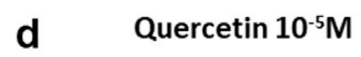

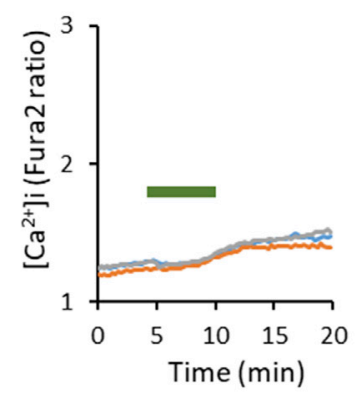

g

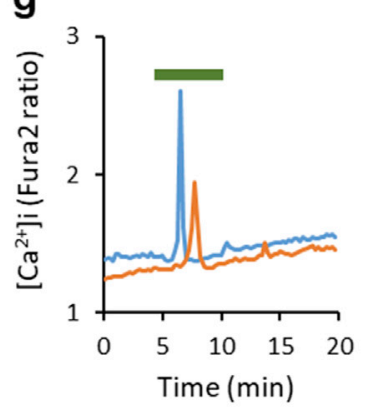

e Quercetin $10^{-8} \mathrm{M}$

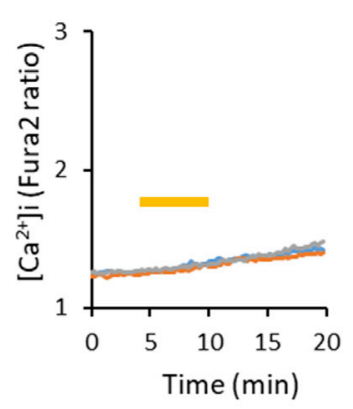

h

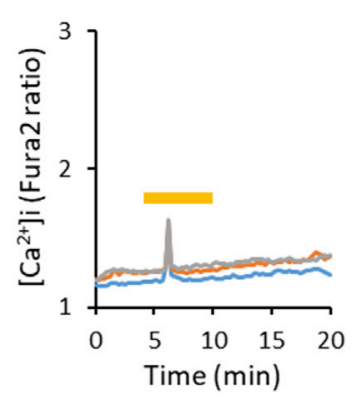

i

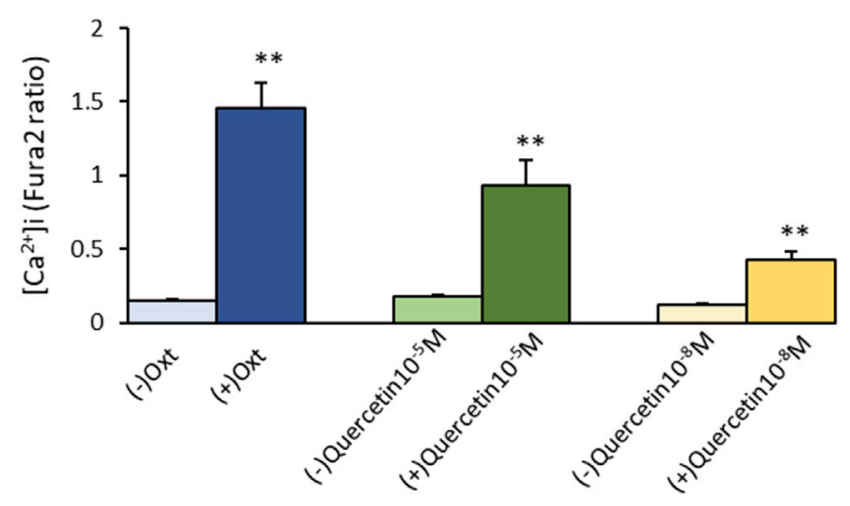

Fig. 9. The change of plasma quercetin levels after oral KKT administration and the effects of quercetin on $\left[\mathrm{Ca}^{2+}\right]_{i}$ in $\mathrm{OTR}$ expressing HEK293 cells. a: Plasma quercetin concentration after oral KKT (500 mg/kg) administration at 0, 20, 60 and $120 \mathrm{~min}$ ( $\mathrm{n}=3$ ). b: Typical 
of $75 \mu \mathrm{g} / \mathrm{mL}$ KKT did not further increase the $\left[\mathrm{Ca}^{2+}\right]_{i}$ level compared to that of the level of $50 \mu \mathrm{g} / \mathrm{mL} \mathrm{KKT}$, $50 \mu \mathrm{g} / \mathrm{mL}$ can be considered as a saturated concentration for the effect of KKT on the OTR. The amplitude of $\left[\mathrm{Ca}^{2+}\right]_{i}$ in the $10^{-5} \mathrm{M}$ Oxt was four times higher to that of the amplitude of $\left[\mathrm{Ca}^{2+}\right]_{i}$ in the $50 \mu \mathrm{g} /$ $\mathrm{mL} \mathrm{KKT.} \mathrm{Therefore,} \mathrm{it} \mathrm{is} \mathrm{suggested} \mathrm{that} \mathrm{KKT} \mathrm{induces}$ moderate activation of OTR compared with Oxt itself.

\subsection{KKT activates PVN Oxt neuron by directly interacting with OTR}

From measurement of $\left[\mathrm{Ca}^{2+}\right]_{i}$ level upon application of KKT, the OTR can be considered as a key factor that mediates the effect of KKT on activating the PVN Oxt neurons. However, it was not clear as to whether KKT directly acts on OTR or simply modifies the receptor property. We therefore treated the OTR-expressing HEK293 cells with the OTR antagonist, H4928, and measured the $\left[\mathrm{Ca}^{2+}\right]_{i}$ level. We showed that $10^{-7} \mathrm{M}$ Oxt slightly increased $\left[\mathrm{Ca}^{2+}\right]_{i}$ in the HEK293 cells without transfection of OTR (OTR(-)) (Fig. 5a), but dramatically increased $\left[\mathrm{Ca}^{2+}\right]_{i}$ in the OTR-transfected cells (OTR $\left.(+)\right)$ (Fig. 5 b). However, pre-treatment of $\mathrm{H} 4928$ reduced the increase in $\left[\mathrm{Ca}^{2+}\right]_{i}$ level compared with the increase in $\left[\mathrm{Ca}^{2+}\right]_{i}$ level upon application of a single Oxt in the OTR $(+)$ cells (Fig. $5 c$ ). Pretreatment of $\mathrm{H} 4928$ significantly reduced $\left[\mathrm{Ca}^{2+}\right]_{\mathrm{i}}$ level by $50 \%$ upon application of Oxt and there were no significant differences in $\left[\mathrm{Ca}^{2+}\right]_{i}$ amplitude when compared with single application of Oxt on OTR(-) cells (Fig. 5g). Similar results were obtained from experiments using KKT. In addition, KKT $50 \mu \mathrm{g} / \mathrm{mL}$ slightly increased $\left[\mathrm{Ca}^{2+}\right]_{i}$ in the OTR(-) cells (Fig. 5d), and resulted in an apparent increase in $\left[\mathrm{Ca}^{2+}\right]_{\mathrm{i}}$ in the OTR $(+)$ cells (Fig. 5e). Pre-treatment of $\mathrm{H} 4928$ reduced the increase in $\left[\mathrm{Ca}^{2+}\right]_{i}$ level compared with a single KKT application (Fig. 5f). Pre-treatment of $\mathrm{H} 4928$ significantly reduced $\left[\mathrm{Ca}^{2+}\right]_{i}$ level by $50 \%$ upon application of KKT, and there were no significant differences in $\left[\mathrm{Ca}^{2+}\right]_{\mathrm{i}}$ amplitude when compared with a single application of KKT on OTR( - ) cells (Fig. 5h).

In order to determine whether this observed effect in OTR(+) cells also occurs in rat PVN Oxt neurons, we used brain slices containing PVN from Oxt-
mRFP rats, and measured the change in membrane potential and firing frequency of Oxt neurons upon applying KKT with H4928. As shown in Fig. $5 i$ and $\mathbf{j}$, the PVN Oxt neurons were less activated (Fig. 5i; $25 \%$ of examined PVN Oxt neurons), or failed to be activated (Fig. 5j; 75\% of examined PVN Oxt neurons) by KKT $(500 \mu \mathrm{g} / \mathrm{mL})$ application in the presence of H4928. There were no changes in firing frequency (Fig. 5k) or membrane potential (Fig. 5l) upon applying KKT on H4928 pre-treated PVN Oxt neurons. These results indicate that KKT activates PVN Oxt neurons directly via OTR.

\subsection{Clarification of crucial crude drugs that activate Oxt neurons in KKT}

The clinically used Japanese Kampo/herbal medicines are based on a systematic combination of crude drugs. KKT is composed of 14 different crude drugs: Astragali Radix, Ginseng Radix, Zizyphi Fructus (ZF), Angelicae Acutilobae Radix (AR), Zingiberis Rhizoma (ZR), Polygalae Radix, Atractylodis Lanceae Rhizoma, Saussureae Radix, Gardenia Fructus, Longan Arillus, Bupleuri Radix, Zizyphi Semen, Glycyrrhizae Radix and Poria. There are three other Kampo/ herbal medicines that include some of the above crude drug components of KKT (Hochuekkito, Shikunshito, Ninjinto). As shown in Table 1, in order of Hochuekkito, Shikunshito and Ninjinto, they gradually lose the crude drug components that are present in KKT. Therefore, we considered that comparing the activating effects of these three Kampo/herbal medicines on PVN Oxt neurons would allow us to pinpoint the crucial crude drugs that activate Oxt neurons. When measuring Oxt neuron activity using a brain slice patch clamp, Hochuekkito activated PVN Oxt neurons similar to that of KKT (Fig. $6 a-c)$. On the other hand, Shikunshito did activate PVN Oxt neurons, although activation took a longer time compared to KKT (Fig. $6 \mathrm{~d}-\mathrm{f}$ ). Ninjinto failed to activate the PVN Oxt neurons (Fig. $6 \mathrm{~g}-\mathrm{i}$ ). Therefore, by comparing the components of these three Kampo/herbal medicines (Table 1), we narrowed down the candidates to three crude drugs; $Z F, A R$, and $Z R$. These three crude drugs are absent in Ninjinto, which failed to activate Oxt neurons. 
We then applied these three crude drugs individually and measured the $\left[\mathrm{Ca}^{2+}\right]_{i}$ level in single PVN Oxt neurons (Fig. 7a-i). The administration of $Z F$ and $Z R$ to single PVN neurons increased $\left[\mathrm{Ca}^{2+}\right]_{\mathrm{i}}$. The amplitude of $\left[\mathrm{Ca}^{2+}\right]_{i}$ and the percentage of each responsive neuron were increased followed by ascending concentration of each crude drug. Upon application of $50 \mu \mathrm{g} / \mathrm{mL} \mathrm{ZF,} \mathrm{47 \%} \mathrm{PVN} \mathrm{neurons}$ responded to $Z F$, and $33 \%$ of $Z F$-responsive neurons were identified as Oxt neurons. On the other hand, upon application of $50 \mu \mathrm{g} / \mathrm{mL} \mathrm{ZR,} \mathrm{60 \%} \mathrm{of} \mathrm{PVN}$ neurons responded to $Z R$, and $89 \%$ of $Z R$-responsive neurons were identified as Oxt neurons. With regards to $A R, 5 \mu \mathrm{g} / \mathrm{mL}$ but not $50 \mu \mathrm{g} / \mathrm{mL}$ AR increased $\left[\mathrm{Ca}^{2+}\right]_{i}$. There was no dose-dependent response in $\left[\mathrm{Ca}^{2+}\right]_{i}$ amplitude or incidence of $A R$ responsive neurons. However, upon application of $50 \mu \mathrm{g} / \mathrm{mL} \mathrm{AR}, 32 \%$ of PVN neurons responded to $A R$, and $29 \%$ of $A R$-responsive neurons were identified as Oxt neurons.

In order to examine whether the combination of these three crude drugs explains the activation of PVN Oxt neurons by KKT, the amplitude of $\left[\mathrm{Ca}^{2+}\right]_{\mathrm{i}}$, upon application of mixture of three crude drugs (50 $\mu \mathrm{g} / \mathrm{mL}$ each) (MIX) and KKT $(50 \mu \mathrm{g} / \mathrm{mL})$, was compared in the PVN neurons. The MIX increased the amplitude of $\left[\mathrm{Ca}^{2+}\right]_{i}$ to same level as that of $50 \mu \mathrm{g} / \mathrm{mL}$ KKT (Fig. 7j, k). Approximately $44 \%$ of the measured PVN neurons responded to MIX and KKT. Among these neurons, over $50 \%$ were Oxtpositive neurons. These results indicate that the three crude drugs in MIX are indeed the key factors to activate PVN Oxt neurons, and also that a combination of these three crude drugs is important to induce KKT's activating effect.

\subsection{Identification of chemicals that activate OTR}

Since we found KKT activates Oxt neurons by directly interacting with OTR and that the crucial crude drugs for the activation being $Z F, A R$ and $Z R$, we attempted to identify the chemicals that activate OTR within $Z F, A R$ and $Z R$. We examined the effects of chemicals composing $Z F, A R$ and $Z R$ by monitoring $\left[\mathrm{Ca}^{2+}\right]_{i}$ levels in OTR expressed HEK 293 cells. Based on information provided by the manufacturer (Tsumura \& Co.) and previous reports from the past, we have analyzed the chemical compounds included in $Z F$ as rutin, ursolic acid, scopoletin, jujuboside A, B, betulinic acid [28-30] and $A R$ as ( $Z$ )-butilidenephatalide, bergapten, umbelliferon, xanthotoxin, $p$-cymene, $\beta$-sitosterol, sensyunolide $H$, senkyunolide A, falcarindol, levistolide $\mathrm{A}$ [31-35] and $Z R$ as of [6]-gingerol, [8]-gingerol, [10]-gingerol, zingerone, [6]-shogaol, [8]- shogaol, [6]-paradol [36,37]. As shown in Fig 8, 2 chemicals (rutin, ursolic acid) in $Z F, 3$ chemicals $((Z)$-butilidenephatalide, $p$-cymene, senkyunolide A) in $A R$ and 2 chemicals ([6]-shogaol, [8]-shogaol) in $Z R$ showed increase in $\left[\mathrm{Ca}^{2+}\right]_{i}$ levels upon its application, indicating combination of these chemicals may contribute to the effects of KKT on Oxt neurons. However, we failed to measure $\left[\mathrm{Ca}^{2+}\right]_{i}$ under application of scopoletin and umbelliferone due to toxicity induced by interaction of excitation light.

\subsection{The change of plasma quercetin and carvacrol after KKT administration}

In order to examine the bioactivity of metabolites of rutin and $p$-cymene [38,39], plasma concentrations of quercetin and carvacrol were measured at 20, 60 and 120 min after oral administration of KKT $(500 \mathrm{mg} / \mathrm{kg})$. Carvacrol was not detected in plasma at any time points in all rats. However, quercetin was detected in all time points. As shown in Fig. 9a, plasma concentration of quercetin reached approximately $15 \mathrm{nM}$ at $60 \mathrm{~min}$ after oral KKT administration. In addition, the of activation of OTR by quercetin was confirmed using OTR-expressing HEK 293 cells. As expected, both $10^{-5} \mathrm{M}$ and $10^{-8} \mathrm{M}$ quercetin increased $\left[\mathrm{Ca}^{2+}\right]_{\mathrm{i}}$ in OTR-expressing cells, with no effect on non-OTR-expressing cells (Fig. 9ch). $10^{-8} \mathrm{M}$ quercetin, which corresponded to plasma quercetin levels at $20 \mathrm{~min}$ after oral KKT administration, showed ability to increase $\left[\mathrm{Ca}^{2+}\right]_{i}$ by $30 \%$ OTR expressing cells compared to increase $\left[\mathrm{Ca}^{2+}\right]_{\mathrm{i}}$ observed by the application of $10^{-7} \mathrm{M}$ Oxt (Fig. 9i).

\section{Discussion}

The current study demonstrated for the first time that traditional Japanese medicine, KKT, has a potential to activate Oxt neuron through OTR. Compared with the activation effect of Oxt itself, the activation of OTR by KKT was moderate (Fig. 4). However, we have found that KKT have certain potential to activate OTR.

Because approximately half of Oxt neurons in the PVN express OTR, Oxt neurons with OTR may be specifically activated by KKT and secrete Oxt. In support of this idea, all Oxt neurons were not activated by KKT in vivo or in vitro. Oral or ip administration of KKT induced c-Fos in approximately $15 \%$ of Oxt neurons, and $37.5 \%$ of KKT-responsive neurons were Oxt neurons.

KKT is clinically used in Japan, and is known to be effective in treating psychological stress disorders. Recently, KKT's effectiveness in the treatment of 
memory impairment and Alzheimer's disease was also reported $[19,20,39,40]$. These reports indicate that KKT has a therapeutic effect by modulating CNS functions.

Several studies have investigated the pharmacological mechanisms induced by KKT on the CNS. Watari et al. reported that KKT may improve tau phosphorylation and axonal atrophy accompanied by increased protein phosphatase $2 \mathrm{~A}$ activity in a mouse model of Alzheimer's disease [20]. Several other reports have indicated that KKT may alter the binding properties of neurotransmitters to receptors [41-43]. However, all these suggested mechanisms are based on the chronic effect of KKT.

Oxt neurons are distributed in the PVN and SON. However, in the present study, c-Fos expressions were found after both oral and ip administration of KKT in the PVN. Oxt neurons in the PVN are considered to be involved in the regulation of psychological stress and mood. This is because PVN Oxt neurons project to areas such as the amygdala, hippocampus, and lateral septum, which are considered to be involved in mood control and stress adaptation [44]. In addition, abundant expressions of OTR were found in these brain areas $[45,46]$. The activation of OTR induced by KKT shown in the present study raises the possibility that, aside from effects reported by others, the novel effect mediated by OTR shown in this study may also underlie the clinical effect of KKT.

Recently, evidence is being gathered for the clinical use of Oxt. Among the suggested clinical uses, Oxt for the treatment of autism has been gaining most attention. Autism is a neurodevelopmental disorder characterized by restricted interest and impaired social communication. A number of human studies were performed to evaluate the effect of Oxt for the treatment of autism, and most of these studies revealed a positive outcome [13,15]. In addition, Oxt may also be effective in treating obesity due to overeating [14]. These studies suggest that manipulation of the Oxt system in the CNS may be clinically beneficial. However, such treatment is limited to the application of Oxt itself (mainly nasal application), and there have been no reports of pharmaceutical drugs that can reach and activate OTR, thereby inducing the release of endogenous Oxt in the brain. Development of an Oxt analogue or drug that can stimulate Oxt release is still controversial, but such a drug may have strong clinical potential for Oxt-related disorders like autism or obesity. Our study suggests that KKT can directly activate Oxt neurons by acting on the OTR and stimulate Oxt release in the brain. Therefore, KKT may have potential as a new pharmacological agent in targeting Oxt neurons and OTR in the CNS. Another advantage of KKT as an Oxt neuron activator is that it can be orally administered. Because Oxt is neuropeptide, it can only be administered peripherally by injection or nasal administration. The present study showed that oral administration of KKT induced c-Fos expression on PVN Oxt neurons in a similar way to that of ip injection. Therefore, orally administered KKT (at least its critical ingredient that activates Oxt neurons) can overcome the blood-brain barrier (BBB) and reach the CNS to show its effect. Supporting this hypothesis, it was reported that the metabolites of Glycyrrhizae and Atractylodes, which are both components of KKT, can overcome the BBB $[47,48]$.

In the present study, we have also clarified that a combination of the three crude drugs $(Z F, A R$ and $Z R)$ composing KKT is the key factors in activating PVN Oxt neurons. Of these crude drugs, $Z R$ may be the one that specifically contributes to the activation of the Oxt neurons, since $89 \%$ of $Z R$-responsive neurons were Oxt neurons. The chemical components of these crude drugs that were capable of activating OTR were rutin, ursolic acid for $Z F$ and (Z)-butilidenephatalide, $p$-cymene, senkyunolide A for $A R$ and [6]-shogaol [8],-shogaol for $Z R$. Because there are 54 compounds identified in only ZF [49], we concentrated in testing part of the components in these crude drugs. Thus, it is possible that other compounds in KKT may also activate OTR.

In order to evaluate from tested compounds as potentials of being agonists of OTR, we calculated response of each components to that of control (Supplemental Fig. 1). Although, the response of KKT to control was approximately 5 times in each experiment of testing each crude drug (red arrows), the response of $A R$ was only with high response with approximately 18 times to that of control. The crude drugs, which responses was over 2.5 times (half response to KKT) were only 3 chemical components, rutin (2.8 times), (Z)-butylidenephtalide (3.2 times) and senkynolide A (3.9 times). These data suggested that $A R$ is the strongest OTR agonist among 3 crude drugs, and a potential OTR agonists were rutin, $(Z)$-butylidenephtalide and senkyunolide A. Supporting this, only $5 \mu \mathrm{g} / \mathrm{mL}$ AR was able to significantly increase the response of $\left[\mathrm{Ca}^{2+}\right]_{i}$ as shown in Fig. 7.

On the other hand, although the response to $Z R$ were 3.5 times to control, there were no chemical component, which responded with more than 2.5 
times to control in $Z R$. The data suggested $Z R$ as crude drug with the strongest synergistic effects. The contribution of synergistic effect is reported in the mechanism of Kampo medicine. For example, in the Kampo medicine Daikenchuto, its chemical component [6]-shogaol and [6]-gingerol are unable to activate voltage-activated cation channels, but become able to activate these voltage-activated cation channels after other chemical component, hydroxy- $\alpha$-sanshool, block two-pore-domain potassium leak channels (KCNK3 and KCNK9) [50]. Similar to synergistic mechanism reported in components of Daikenchuto, it is possible to consider that such mechanisms are present in chemical components of $Z R$.

Although further study is required to clarify the underlying mechanism of these three crude drugs, and seven chemical components to induce Oxt neuron activation, our present data indicate the clinical possibility of these crude drugs or chemical components for treating Oxt-related disorders. It is possible that these seven chemical components may fulfill the criteria of bioactive chemical markers, defined as a group of chemo-markers with pharmacological activities comparable to whole KKT. Detail study to determine the bioactive chemical markers for KKT is required for the quality control, correct safety use of KKT in the future [51,52].

Common crude drugs, Astragali Radix and Bupleuri Radix, which are contained in KKT and Hochuekkito are not examined in the present study. It remains the possibility that these two crude drugs are also related to OTR activation. Further study about Astragali Radix and Bupleuri Radix are needed in the future.

Although our present data is mainly based on $e x$ vivo condition and further functional studies are required, this is the first study to show clearly in cellular level that KKT has potential to activate Oxt neurons through OTR. Considering the effects of Oxt to treat so many disorders, the effects of KKT shown in this study has strong potential for future clinical use.

Although the present study focused on the effect of KKT on the CNS, OTR is expressed in various peripheral tissues, such as muscle [12,53], osteoblasts [54] and the pancreas [55]. Oxt contributes to the maintenance and regeneration of muscle cells [12], increases trabecular bone volume [11], and promotes insulin secretion from pancreatic $\beta$-cells [23]. Taking our present findings, that KKT can activate the OTR, into consideration, KKT may have a positive effect in peripheral tissues, as well as the CNS. These are important issues that should be investigated in the future.

\section{Conclusion}

In conclusion, we have identified a novel effect of KKT on the activation of PVN Oxt neurons via the OTR. We suggest that this acute effect of KKT on Oxt neurons and OTR may contribute to the treatment of psychological and neurological disorders. As manipulation of the Oxt system in the CNS may be a therapeutic target for various diseases such as autism, KKT could be introduced as a new potential pharmacological agent.

\section{Author Contributions}

Y.M and K.S conceived and designed the project. Y.M performed in the vivo experiment and the histological analysis. K.S. performed electrophysiological experiments. S. Y. performed cytosolic $\mathrm{Ca}^{2+}$ measurements. S.H designed the OTR vector for transfection. S. H and T.O prepared the OTRtransfected cultured cells, and provide the critical observation. S.M. performed experiments of pharmacokinetics. K. N. and H. Y. K provided valuable comments and suggestions. Y. U provided the OxtmRFP rats as well as valuable comments on the study. Y.M, P. P and K.S wrote the manuscript. All authors discussed the results and contributed to the final manuscript.

\section{Conflicts of interests}

The authors declare no competing financial or non-financial interests.

\section{Acknowledgements}

The authors appreciate Prof. Kazuto Kobayashi and Dr. Shigeki Kato of the Department of Molecular Genetics, Institute of Biomedical Sciences, Fukushima Medical University for providing the RFP-encoding gene. The authors thank Tsumura Co. for kindly providing KKT, the individual crude drugs and chemical components included in KKT. The authors appreciate Dr. Takeyasu Kakamu of Department of Hygiene and Preventive Medicine Fukushima Medical University for providing advice of statistical analysis.

This work was supported by a Grant-in-Aid for Scientific Research (C) (18K08483 to Y. M, 26461366 to K.S). 


\section{Appendix.}

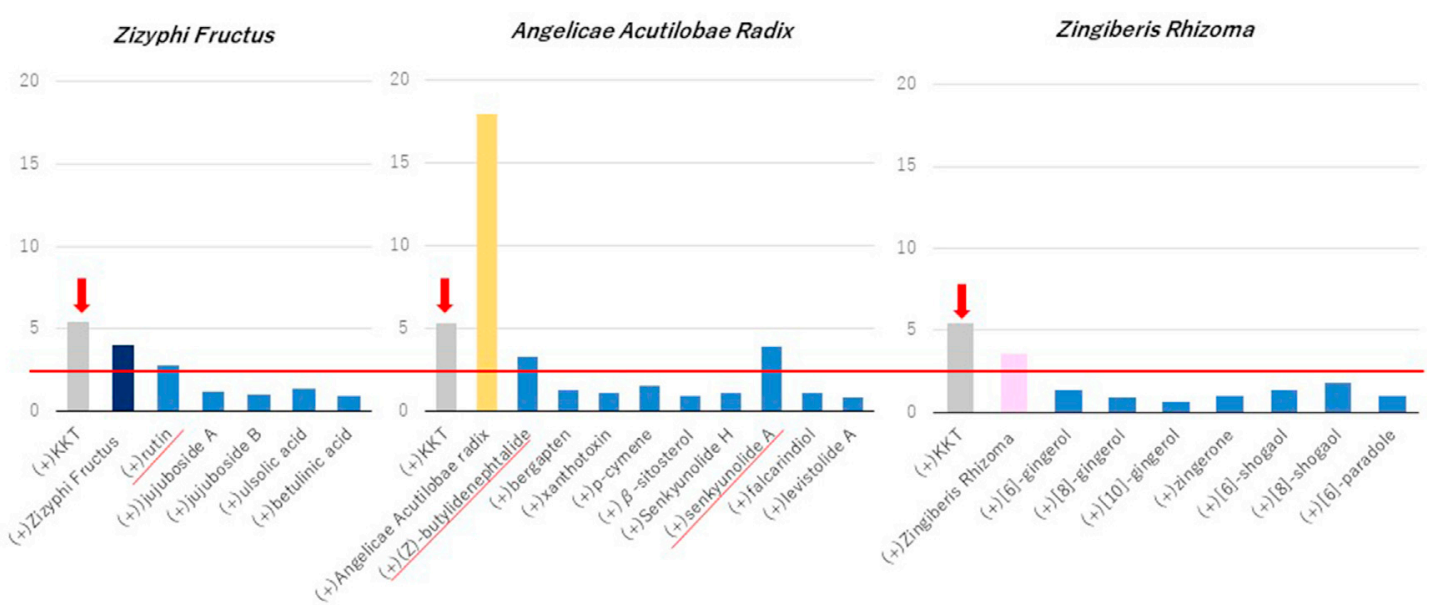

Fig. S1.

\section{References}

[1] Kiss A, Mikkelsen JD. Oxytocin-anatomy and functional assignments: a minireview. Endocr Regul 2005;39:97-105.

[2] Unvas-Moberg K, Bruzelius G, Alster P, Lundeberg T. The antinociceptive effect of non-noxious sensory stimulation is mediated partly through oxytocinergic mechanisms. Acta Physiol Scand 1993;149:199-204.

[3] Leckman JF, Goodman WK, North WG, Chappell PB, Price LH, Pauls DL, et al. The role of central oxytocin in obsessive compulsive disorder and related normal behavior. Psychoneuroendocrinology 1994;19:723-49.

[4] Peters S, Slattery DA, Uschold-Schmidt N, Reber SO, Neumann ID. Dose-dependent effects of chronic central infusion of oxytocin on anxiety, oxytocin receptor binding and stress-related parameters in mice. Psychoneuroendocrinology 2014;42:225-36.

[5] Mantella RC, Vollmer RR, Li X, Amico JA. Female oxytocindeficient mice display enhanced anxiety-related behavior. Endocrinology 2003;144:2291-6.

[6] McQuaid RJ, McInnis OA, Stead JD, Matheson K, Anisman H. A paradoxical association of an oxytocin receptor gene polymorphism: early-life adversity and vulnerability to depression. Front Neurosci 2013;128.

[7] Kumsta R, Hummel E, Chen FS, Heinrichs M. Epigenetic regulation of the oxytocin receptor gene: implications for behavioural neuroscience. Front Neurosci 2013;7:83.

[8] Maejima Y, Sedbazar U, Suyama S, Kohno D, Onaka T, Takano E, et al. Nesfatin-1-regulated oxytocinergic signaling in the paraventricular nucleus causes anorexia through a leptin-independent melanocortin pathway. Cell Metabol 2009; 10:355-65.

[9] Maejima Y, Iwasaki Y, Yamahara Y, Kodaira M, Sedbazar U, Yada T. Peripheral oxytocin treatment ameliorates obesity by reducing food intake and visceral fat mass. Aging 2011;3: 1169-77.

[10] Maejima Y, Aoyama M, Sakamoto K, Jojima T, Aso Y, Takasu K, et al. Impact of sex, fat distribution and initial body weight on oxytocin's body weight regulation. Sci Rep 2017;7: 8599.

[11] Elabd C, Basillais A, Beaupied H, Breuil V, Wagner N, Scheideler $\mathrm{M}$, et al. Oxytocin controls differentiation of human mesenchymal stem cells and reverses osteoporosis. Stem Cell 2008;26:2399-407.
[12] Elabd C, Cousin W, Upadhyayula P, Chen RY, Chooljian MS, $\mathrm{Li} \mathrm{J}$, et al. Oxytocin is an age-specific circulating hormone that is necessary for muscle maintenance and regeneration. Nat Commun 2014;5:4082

[13] Kosaka H, Munesue T, Ishitobi M, Asano M, Omori M, Sato $\mathrm{M}$, et al. Long-term oxytocin administration improves social behaviors in a girl with autistic disorder. BMC Psychiatr 2012;12:110.

[14] Ott V, Finlayson G, Lehnert H, Heitmann B, Heinrichs M, Born J, et al. Oxytocin reduces reward-driven food intake in humans. Diabetes 2013;62:3418-25.

[15] Tachibana M, Kagitani-Shimono K, Mohri I, Yamamoto T, Sanefuji W, Nakamura A, et al. Long-term administration of intranasal oxytocin is a safe and promising therapy for early adolescent boys with autism spectrum disorders. J Child Adolesc Psychopharmacol 2013;23:123-7.

[16] Kudo Y, Mori A, Asai M, Kazamatsuri H, Kawakita $Y$, Kurihara M, et al. Clinical evaluation of KAMIKIHI-TO (EK49) in the treatment of psychoneurosis. J Clin Ther Med 1992; 8:2989-3007 [In Japanese, English abstract].

[17] Katoh A, Fujihara H, Ohbuchi T, Onaka T, Hashimoto T, Kawata M, et al. Highly visible expression of an oxytocinmonomeric red fluorescent protein 1 fusion gene in the hypothalamus and posterior pituitary of transgenic rats. Endocrinology 2011;152:2768-74.

[18] Yoshida M, Takayanagi Y, Inoue K, Kimura T, Young LJ, Onaka T, et al. Evidence that oxytocin exerts anxiolytic effects via oxytocin receptor expressed in serotonergic neurons in mice. J Neurosci 2009;29:2259-71.

[19] Tohda C, Nakada R, Urano T, Okonogi A, Kuboyama T. Kamikihi-to (KKT) rescues axonal and synaptic degeneration associated with memory impairment in mouse model of Alzheimer's disease, 5XFAD. Int J Neurosci 2011;121:641-8.

[20] Watari H, Shimada Y, Tohda C. New treatment for Alzheimer's disease, Kamikihito, reverses amyloid- $\beta$-induced progression of tau phosphorylation and axonal atrophy. Evid Based Complement Alternat Med 2014:706487.

[21] Nishizawa K, Yamashita A. Effects of Kamikihi-To, a traditional Chinese medicine, on behavioral changes induced by methyl-beta-carboline-3-carboxylate in mice and rats. Jpn J Pharmacol 1997;75:391-7.

[22] Araki R, Nishida S, Hiraki Y, Li F, Matsumoto K, Yabe T. Kamikihito ameliorates lipopolysaccharide-induced sickness behavior via attenuating neural activation, but not inflammation, in the hypothalamic paraventricular nucleus and 
central nucleus of the amygdala in mice. Biol Pharm Bull 2016:39:289-94.

[23] Maejima Y, Rita RS, Santoso P, Aoyama M, Hiraoka Y, Nishimori $K$, et al. Nasal oxytocin administration reduces food intake without affecting locomotor activity and glycemia with c-Fos induction in limited brain areas. Neuroendocrinology 2015;101:35-44.

[24] Kania A, Gugula A, Grabowiecka A, de Ávila C, Blasiak T, Rajfur Z, et al. Inhibition of oxytocin and vasopressin neuron activity in rat hypothalamic paraventricular nucleus by relaxin-3-RXFP3 signalling. J Physiol 2017;595:3425-47.

[25] Maejima Y, Takahashi S, Takasu K, Takenoshita S, Ueta Y, Shimomura K. Orexin action on oxytocin neurons in the paraventricular nucleus of the hypothalamus. Neuroreport 2017;28:360-6.

[26] Iwasaki Y, Maejima Y, Suyama S, Yoshida M, Arai T, Katsurada $K$, et al. Peripheral oxytocin activates vagal afferent neurons to suppress feeding in normal and leptinresistant mice: a route for ameliorating hyperphagia and obesity. Am J Physiol Regul Integr Comp Physiol 2015;308: R360-9.

[27] Fujitsuka N, Asakawa A, Uezono Y, Minami K, Yamaguchi T, Niijima A, et al. Potentiation of ghrelin signaling attenuates cancer anorexia-cachexia and prolongs survival. Transl Psychiatry 2009;1:e23.

[28] Lam CTW, Chan PH, Lee PSC, Lau KM, Kong AYY, Gong AGW, et al. Chemical and biological assessment of Jujube (Ziziphus jujube)-containing herbal decoctions: induction of erythropoietin expression in cultures. J Chromatogr B Analyt Technol Biomed Life Sci 2016;1026:254-62.

[29] Li YJ, Che ZT, Bi KS, Zu ZM, Li M. Determination of jujubaside A in semen ziziphi spinosae by RP-HPLC. Zhongguo Zhongyao Zazhi 2001;26:309-10 [In Chinese, English abstract].

[30] Li X, Li X, Zhou B, Man S, Gao W, Jing S. Study on the bioactive constituents and in vitro antioxidant and in vivo anti-inflammatory activities of extracts from the fruits of Ziziphus Jujuba Mill. cv. Jinsixiaozao hort. Food Sci Technol Res 2017;23:417-26.

[31] Yi T, Leung KS, Lu GH, Zhang H. Comparative analysis of Ligusticum chuanxiong and related umbelliferous medicinal plants by high performance liquid chromatography-electrospray ionization mass spectrometry. Planta Med 2007;73: 392-8.

[32] Liu X, Liu J, Cai H, Li S, Ma X, Lou Y, et al. Novel characterization of Radix Angelicae Dahuricae before and after the sulfur-fumigation process by combining high performance liquid chromatographic fingerprint and multi-ingredients determination. Phcog Mag 2014;10:338-45.

[33] Chen HC, Tsaia Jr Y, Linb LY, Wu CS, Tai SP, Chen YC, et al. Volatile compounds from roots, stems and leaves of Angelica acutiloba growing in Taiwan. Nat Prod Commun 2014;9: $583-6$.

[34] Takahashi S, Hikino H, Sasaki Y. Pharmacognostical studies on Umbelliferous plants. IX. Studies on 'Toki'. (9). Components of the roots of Angelica acutiloba and A. acutiloba var. Sugiyamae. Yakugaku Zasshi 1958;78:1156-9 [In Japanese, English abstract].

[35] Uto T, Tung NH, Taniyama R, Miyanowaki T, Morinaga O, Shoyama Y. Anti-inflammatory activity of constituents isolated from aerial part of Angelica acutiloba Kitagawa. Phytother Res 2015;29:1956-63.

[36] Peng LQ, Cao J, Du LJ, Zhang QD, Xu JJ, Chen YB, et al. Rapid ultrasonic and microwave-assisted micellar extraction of zingiberone, shogaol and gingerols from gingers using biosurfactants. J Chromatogr A 2017;1515:37-44.

[37] Sun M, Yang YP, Li YJ, Du J, Chen QF, Meng J. Study on chemical composition of zingiberis rhizome carbonisata. Zhong Yao Cai 2016;39:307-11 [In Chinese, English abstract].

[38] Yang J, Lee H, Sung J, Kim Y, Jeong HS, Lee J. Conversion of rutin to quercetin by acid treatment in relation to biological activities. Prev Nutr Food Sci 2019;24:313-20.
[39] Kiskó G, Roller S. Carvacrol and p-cymene inactivate Escherichia coli O157:H7 in apple juice. BMC Microbiol 2005; 5:36.

[40] Egashira N, Manome N, Kurauchi K, Matsumoto $Y$, Iwasaki K, Mishima K, et al. Kamikihi-to, a Kampo medicine, ameliorates impairment of spatial memory in rats. Phytother Res 2007;21:126-9.

[41] Hayashi T, Yamada K, Hasegawa T, Ishihara S, Kameyama T, Morimasa T, et al. Effects of Kamikihito, a traditional Chinese medicine, on neurotransmitter receptor binding in the aged rat brain determined by in vitro autoradiography (1): changes in the $[3 \mathrm{H}] \mathrm{QNB}$ binding. Jpn J Pharmacol 1994;64: 303-6.

[42] Ishihara S, Yamada K, Hayashi T, Hasegawa T, Kameyama T, Morimasa T, et al. Effects of Kamikihito, a traditional Chinese medicine, on neurotransmitter receptor binding in the aged rat brain determined by in vitro autoradiography: changes in dopamine D1 and serotonin 5-HT2A receptor binding. Biol Pharm Bull 1994;17:1132-4.

[43] Yamada K, Hayashi T, Hasegawa T, Ishihara S, Kameyama T, Morimasa T, et al. Effects of Kamikihito, a traditional Chinese medicine, on neurotransmitter receptor binding in the aged rat brain determined by in vitro autoradiography (2): changes in GABAA and benzodiazepine receptor binding. Jpn J Pharmacol 1994;66:53-8.

[44] Buijs RM, Swaab DF, Dogterom J, van Leeuwen FW. Intraand extrahypothalamic vasopressin and oxytocin pathway in the rat. Cell Tissue Res 1978;186:423-33.

[45] Gould BR, Zingg HH. Mapping oxytocin receptor gene expression in the mouse brain and mammary gland using an oxytocin receptor-LacZ reporter mouse. Neuroscience 2003; 122:155-67.

[46] Gimpl G, Fahrenholz F. The oxytocin receptor system: structure, function, and regulation. Physiol Rev 2001;81: 629-83.

[47] Tabuchi M, Imamura S, Kawakami Z, Ikarashi Y, Kase Y. The blood-brain barrier permeability of $18 \beta$-glycyrrhetinic acid, a major metabolite of Glycyrrhizin in Glycyrrhiza root, a constituent of the traditional Japanese medicine Yokukansan. Cell Mol Neurobiol 2012;32:1139-46.

[48] Nahata M, Mizuhara Y, Sadakane C, Watanabe J, Fujitsuka N, Hattori T. Influence of food on the gastric motor effect on Kampo medicine rikkunshito in rat. Neuro Gastroenterol Motil 2018:30.

[49] Khan MN, Ul Haq F, Rahman S, Ali A, Musharraf SG. Metabolite distribution and correlation studies of Ziziphus jujuba and Ziziphus nummularia using LC-ESI-MS/MS. J Pharmaceut Biomed Anal 2020;178:112918.

[50] Kono T, Shimada M, Yamamoto M, Kaneko A, Oomiya Y, Kubota K, et al. Complementary and synergistic therapeutic effects of compounds found in Kampo medicine: analysis of daikenchuto. Front Pharmacol 2015;6:159.

[51] Yang Z, Shao Q, Ge Z, Ai N, Zhao X, Fan X. A bioactive chemical markers based strategy for quality assessment of botanical drugs: xuesaitong injection as a case study. Sci Rep 2017;7:2410.

[52] Lau CB, Yue GG, Lau KM, Chan YY, Shaw PC, Kwok HF, et al. Method establishment for upgrading chemical markers in pharmacopoeia to bioactive markers for biological standardization of traditional Chinese medicine. J Tradit Complement Med 2018;9:179-83.

[53] Gajdosechova L, Krskova K, Olszanecki R, Zorad S. Differential regulation of oxytocin receptor in various adipose tissue depots and skeletal muscle types in obese Zucker rats. Horm Metab Res 2015;47:600-4.

[54] Copland JA, Ives KL, Simmons DJ, Soloff MS. Functional oxytocin receptors discovered in human osteoblasts. Endocrinology 1999;140:4371-4.

[55] Suzuki M, Honda Y, Li MZ, Masuko S, Murata Y. The localization of oxytocin receptors in the islets of Langerhans in the rat pancreas. Regul Pept 2013;183:42-5. 
[56] Yu XL, Li YN, Zhang H, Su YJ, Zhou WW, Zhang ZP, et al. Rutin inhibits amylin-induced neurocytotoxicity and oxidative stress. Food Funct 2015;6:3296-306.

[57] Yu HH, Hur JM, Seo SJ, Moon HD, Kim HJ, Park RK, et al. Protective effect of ursolic acid from Cornus officinalis on the hydrogen peroxide-induced damage of HEI-OC1 auditory cells. Am J Chin Med 2009;37:735-46.

[58] Yu R, Chen JA, Xu J, Cao J, Wang Y, Thomas SS, et al. Suppression of muscle wasting by the plant-derived compound ursolic acid in a model of chronic kidney disease. J Cachexia Sarcopenia Muscle 2017;8:327-41.

[59] Zhang M, Qian C, Zheng ZG, Qian F, Wang Y, Thu PM, et al. Jujuboside A promotes $A \beta$ clearance and ameliorates cognitive deficiency in Alzheimer's disease through activating Axl/HSP90/PPAR $\gamma$ pathway. Theranostics 2018;8: $4262-78$.

[60] Zhao Y, Zhang X, Li J, Bian Y, Sheng M, Liu B, et al. Jujuboside $B$ reduces vascular tension by increasing $\mathrm{Ca} 2+$ influx and activating endothelial nitric oxide synthase. PloS One 2016;11:e0149386.

[61] Ackermann A, Karagöz AÇ, Ghoochani A, Buchfelder M, Eyüpoglu I, Tsogoeva SB, et al. Cytotoxic profiling of artesunic and betulinic acids and their synthetic hybrid compound on neurons and gliomas. Oncotarget 2017;8:61457-74.

[62] Chen M, Ko WC. Lack of effect of Z-butylidenephthalide on presynaptic N-type $\mathrm{Ca}^{2+}$ channels in isolated Guinea-pig ileum. Naunyn-Schmiedeberg's Arch Pharmacol 2016;389: 159-66.

[63] He Y, Zisan Z, Lu Z, Zheng L, Zhao J. Bergapten alleviates osteoarthritis by regulating the ANP32A/ATM signaling pathway. FEBS Open Bio 2019;9:1144-52.

[64] Lee SB, Lee WS, Shin JS, Jang DS, Lee KT. Xanthotoxin suppresses LPS-induced expression of iNOS, COX-2, TNF- $\alpha$, and IL-6 via AP-1, NF- $\kappa \mathrm{B}$, and JAK-STAT inactivation in RAW 264.7 macrophages. Int Immunopharm 2017;49:21-9.

[65] Wu T, Mazhar Z, Alsayrafi D, Garelnabi M. p-Cymene modulate oxidative stress and inflammation in murine macrophages: potential implication in atherosclerosis. Cardiovasc hematol agents med chem 2019. Online ahead of print. Available at: https://doi.org/10.2174/ 1871525717666191118112310.
[66] Luo Y, Li X, Liu T, Cao Y, Zhang J, Yaseen A, et al. Senkyunolide $\mathrm{H}$ protects against MPP+-induced apoptosis via the ROS-mediated mitogen-activated protein kinase pathway in PC12 cells. Environ Toxicol Pharmacol 2019;65: 73-81.

[67] Hu PY, Liu D, Zheng Q, Wu Q, Tang Y, Yang M. Elucidation of transport mechanism of paeoniflorin and the influence of ligustilide, senkyunolide I and senkyunolide A on paeoniflorin transport through Mdck-Mdr1 cells as blood-brain barrier in vitro model. Molecules 2016;21:300.

[68] Venkatesan T, Choi YW, Lee J, Kim YK. Falcarindiol inhibits LPS-induced inflammation via attenuating MAPK and JAKSTAT signaling pathways in murine macrophage RAW 264.7 cells. Mol Cell Biochem 2018;445:169-78.

[69] Yang Y, Zhang Y, Wang L, Lee S. Levistolide A induces apoptosis via ROS-Mediated ER stress pathway in colon cancer cells. Cell Physiol Biochem 2017;42:929-38.

[70] Ha SK, Moon E, Ju MS, Kim DH, Ryu JH, Oh MS, et al. 6Shogaol, a ginger product, modulates neuroinflammation: a new approach to neuroprotection. Neuropharmacology 2012; 63:211-23.

[71] Dedov VN, Tran VH, Duke CC, Connor M, Christie MJ, Mandadi S, et al. Gingerols: a novel class of vanilloid receptor (VR1) agonists. Br J Pharmacol 2002;137:793-8.

[72] Rasmussen A, Murphy K, Hoskin DW. 10-Gingerol inhibits ovarian cancer cell growth by inducing G2 arrest. Adv Pharmaceut Bull 2019;9:685-9.

[73] Gan H, Zhang Y, Zhou Q, Zheng L, Xie X, Veeraraghavan VP, et al. Zingerone induced caspase-dependent apoptosis in MCF-7 cells and prevents 7,12-dimethylbenz(a)anthraceneinduced mammary carcinogenesis in experimental rats. J Biochem Mol Toxicol 2019;33:e22387.

[74] Gaire BP, Kwon OW, Park SH, Chun KH, Kim SY, Shin DY, et al. Neuroprotective effect of 6-paradol in focal cerebral ischemia involves the attenuation of neuroinflammatory responses in activated microglia. PloS One 2015;10:e0120203.

[75] Shieh PC, Chen YO, Kuo DH, Chen FA, Tsai ML, Chang IS, et al. Induction of apoptosis by [8]-shogaol via reactive oxygen species generation, glutathione depletion, and caspase activation in human leukemia cells. J Agric Food Chem 2010; $58: 3847-54$ 